\title{
WestVirginiaUniversity
}

THE RESEARCH REPOSITORY @ WVU

Graduate Theses, Dissertations, and Problem Reports

2005

\section{Effectiveness of the "common" method in balancing exhaust ventilation systems}

Vivek Balasubramanian

West Virginia University

Follow this and additional works at: https://researchrepository.wvu.edu/etd

\section{Recommended Citation}

Balasubramanian, Vivek, "Effectiveness of the "common" method in balancing exhaust ventilation systems" (2005). Graduate Theses, Dissertations, and Problem Reports. 1654.

https://researchrepository.wvu.edu/etd/1654

This Thesis is protected by copyright and/or related rights. It has been brought to you by the The Research Repository @ WVU with permission from the rights-holder(s). You are free to use this Thesis in any way that is permitted by the copyright and related rights legislation that applies to your use. For other uses you must obtain permission from the rights-holder(s) directly, unless additional rights are indicated by a Creative Commons license in the record and/ or on the work itself. This Thesis has been accepted for inclusion in WVU Graduate Theses, Dissertations, and Problem Reports collection by an authorized administrator of The Research Repository @ WVU. For more information, please contact researchrepository@mail.wvu.edu. 


\title{
Effectiveness of the "Common" Method in Balancing Exhaust Ventilation Systems
}

\author{
Vivek Balasubramanian
}

\author{
Thesis submitted to the \\ College of Engineering and Mineral Resources at \\ West Virginia University \\ in partial fulfillment of the requirements \\ for the degree of
}

\author{
Master of Science \\ in \\ Industrial Engineering
}
Steven Guffey Ph.D., Chair
Robert Creese Ph.D.
Majid Jaraiedi Ph.D.

Department of Industrial and Management Systems Engineering.

\author{
Morgantown, West Virginia \\ 2005
}

Key Words:

HVAC Testing and Balancing (TAB), Dampers, Slide-Gates, Blast-Gates, Exhaust ventilation, Airflow, Hood Static Pressure 


\section{Abstract \\ Effectiveness of the "Common” Method in Balancing Exhaust Ventilation Systems. \\ Vivek Balasubramanian}

Dampers are used to adjust the distribution of airflows in duct systems. The "common"(i.e., most commonly used) method is to adjust each damper in turn so that the airflow through its branch equals the desired level. Typically, the airflow through each branch duct is estimated from the centerline velocity pressure. To test the effectiveness of that approach, dampers were adjusted on a seven branch, full-sized experimental duct system. After adjusting the dampers for a given condition, the percent excess airflow ( $\left.\% \mathrm{Q}_{\text {excess }}\right)$ for the system was estimated as the amount above the ideal fan airflow that would exist if the fan speed were adjusted so that the lowest ratio of airflow to airflow goal for any branch was unity. The lower the value of percent excess airflow, the more perfectly balanced the system was.

The results varied with the level of the target airflows. The excess airflow was least (5.3\%) for the low airflow system. The excess for the moderate ( $8.5 \%)$ was greater than the excess for the perfect targets (6.56\%). These values were much higher than the mean value of $2.13 \%$ found by Dodrill (2004) on the same system for the " $\mathrm{SP}_{\mathrm{h}}$ Goal Ratio" method proposed by Guffey (2005). The pressure in the system was measured. As expected, the pressure in the system increased as the dampers were choked down to achieve the targets. 


\section{Acknowledgements}

I am indebted to a large group of people, all of whom have helped me in some way during my master's program. I would specifically like to thank Dr. Steve Guffey, my supervisor, for his guidance, wisdom, encouragement, and promptness in reviewing my work. I am also indebt to the members of my committee: Dr. Majid Jaraiedi and Dr. Robert Creese. Their comments and suggestions have dramatically improved the quality of my thesis.

Thanks to Nordfab for donating the ductwork.

I would also like to thank Ahmed El-Sotouhy and Michael Dodrill for their help in building the ventilation system. 


\section{Table of Contents}

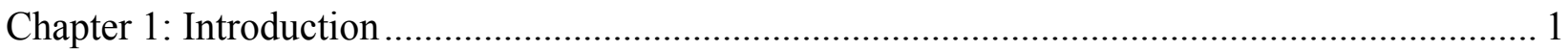

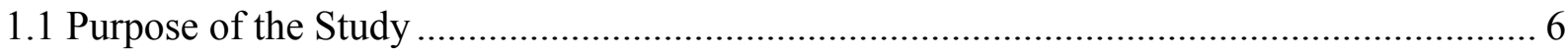

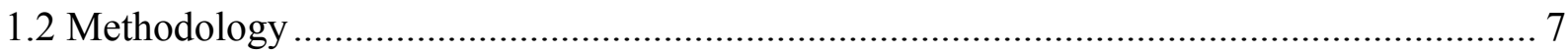

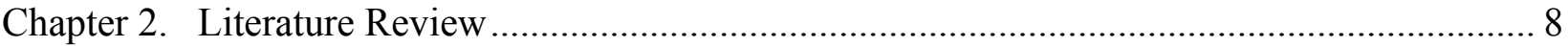

2.1 Sheet Metal and Air Conditioning Contractors' National Association (SMACNA)

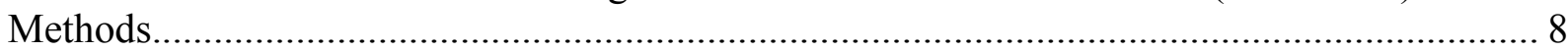

2.2 The American Society of Heating, Refrigerating, and Air-Conditioning Engineers

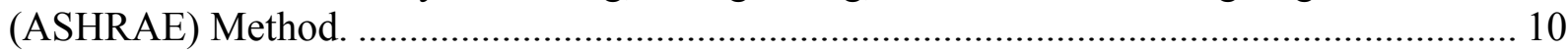

2.3 The American Conference of Governmental Industrial Hygienists (ACGIH) .................. 10

2.4 Guffey Pressure Ratio Method......................................................................................... 11

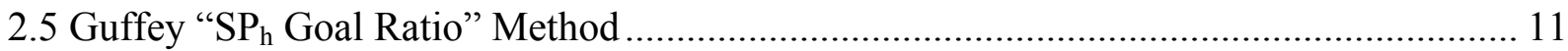

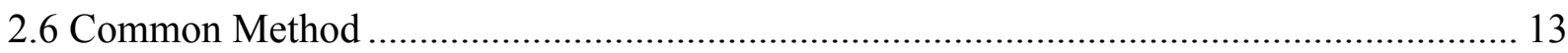

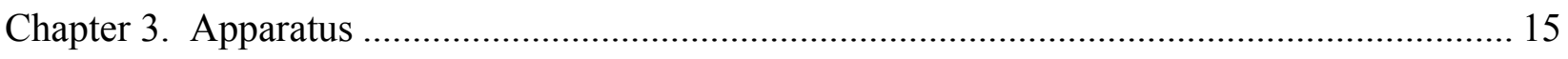

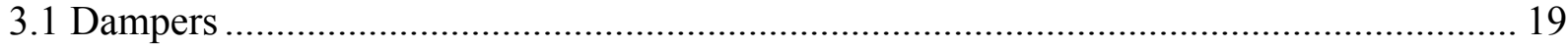

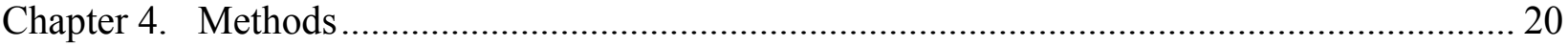

4.1. Pressure and Flow Measurements............................................................................ 20

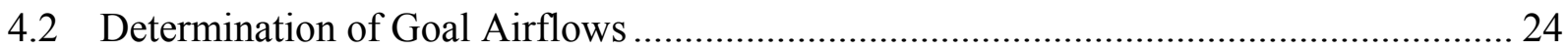

4.3 Calculation of the Goal $V_{c l}$ for Each Branch at Which the System is in Balance ….......... 26

4.4 Determination of the Order in Which the Ducts Must be Adjusted ................................... 27

4.5 Damper Adjustments .............................................................................................. 28

4.6 Determination of Adjustment Effectiveness ………………………………………...... 29

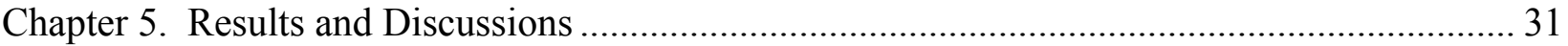

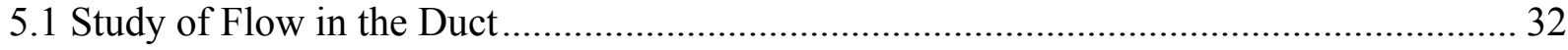

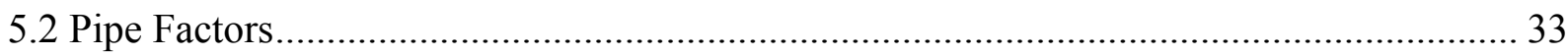

5.3 Deviation Between Target and Final Airflows for Individual Branches ............................ 37

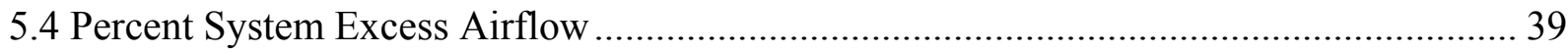

5.5 Comparison of the Common Method to the $\mathrm{SP}_{\mathrm{h}}$ Goal Ratio Method................................. 42

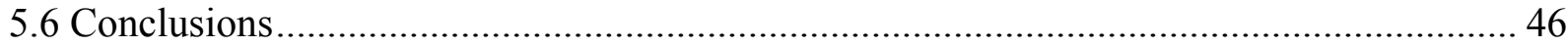

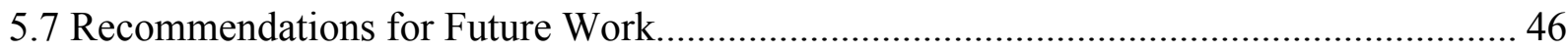

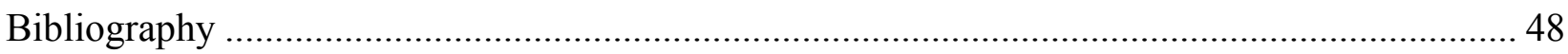

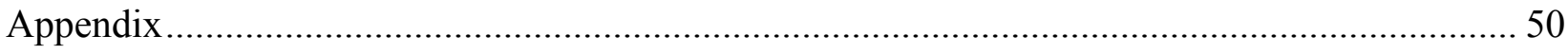




\section{List of Tables}

Table. 1 Specifications of the Ventilation System Used in the Study .................................... 15

Table 2. The Different Target Values for the Branches in $\mathrm{cfm}$. ............................................ 25

Table 3. The Order in Which the Branches are Adjusted .................................................. 28

Table 4. Original, Target and Goal Airflows and Centerline Velocity Target Pressures ............ 29

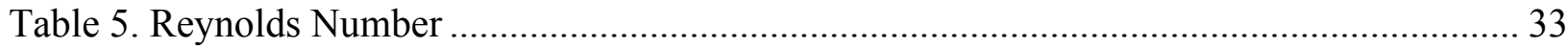

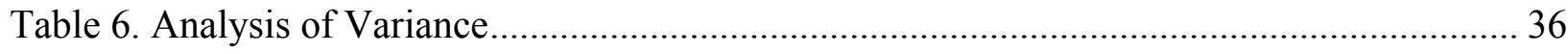

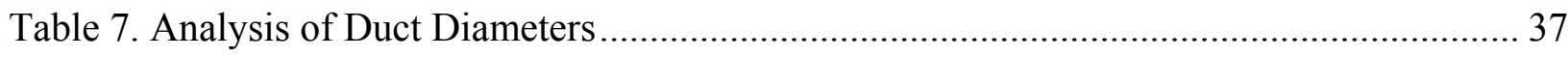

Table 8. The Ratio of the Target Airflow to the Final Airflow for each Branch....................... 38

Table 9. The Ratio of $Q_{\text {final }} / \mathrm{Q}_{\text {Target }}$ at the End of the First Round for the Low Airflow

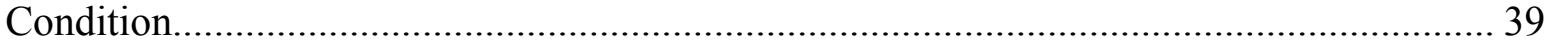

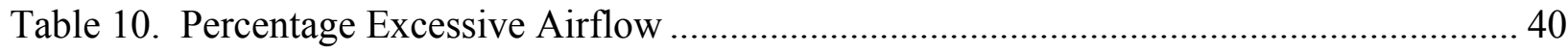

Table 11. The Percent of Excessive Airflow at Different Levels.......................................... 41

Table 12. ANOVA to Test the Significance of Levels of Airflow ......................................... 42

Table 13. Comparison of Results for the Two Methods....................................................... 43 


\section{List of Figures}

Figure 1. Slide Gate Damper Similar to Those Used in This Study (Guffey, 2005).................. 3

Figure 2. Fan Interactions and Adjustments for the Common Method (Guffey, 2005).............. 4

Figure 3. Fan Interactions and Adjustments for the Proportional balancing method.

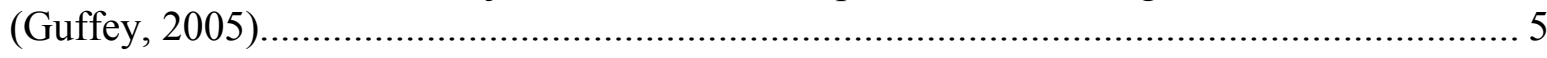

Figure 4. Schematic of the Experimental Ventilation Duct System (Dodrill, 2004)................ 16

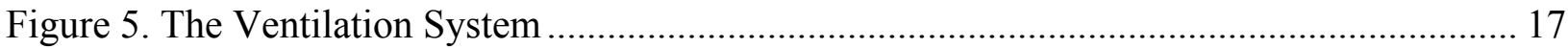

Figure 6. Pitot Traverse Device (ACGIH, 2005) ............................................................. 17

Figure 7. Cross-section of a Pitot tube (ACGIH, 2005). ..................................................... 18

Figure 8. Slide Gate Damper Full Open ............................................................................ 19

Figure 9. Slide Gate Dampers used for the Study.......................................................... 19

Figure 10.a. Measurements of Total Pressures using a Pitot tube (Guffey, 2005)................... 20

Figure 10.b. Measurements of Static Pressures using a Pitot tube (Guffey, 2005)................... 21

Figure 10.c. Measurements of Velocity Pressures using a Pitot tube (Guffey, 2005)................ 21

Figure 11. A Hooded Branch (Branch Number Two) ....................................................... 24

Figure 12. Target airflows for each Branch...............................................................25

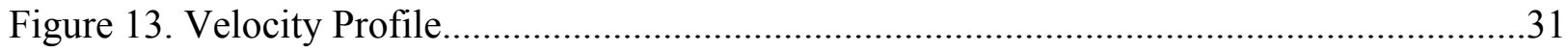

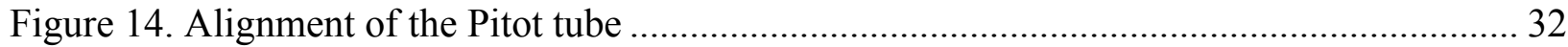

Figure 15. Plot of Pipe Factors Vs Branch No.......................................................................... 34

Figure 16. Branch Number vs. Percent (Q Final / $\left.Q_{\text {Target }}\right)$...................................................... 38

Figure 17. Percentage of Excessive Airflow for both Methods ............................................ 44 


\section{Abbreviations and Terminology}

Q

$\mathrm{V}$

A

DF

$\mathrm{Q}_{\mathrm{d}}$

original

target

Qoriginal(i)

$\mathrm{Q}_{\mathrm{br}}$

$\mathrm{Q}_{\text {final }}$

Qgoal(i)

Qtarget

Qtarget(i)

$\mathrm{Q}_{\text {fan }}$

Qfan original

$\mathrm{Q}_{\text {fan goal }}$

$\mathrm{SP}_{\mathrm{h}}$

$\mathrm{SP}_{\mathrm{h} \text { original }}$

$\mathrm{SP}_{\mathrm{h} \text { goal }}$

$\mathrm{SP}_{\mathrm{h} \text { target round } 1}$

$\mathrm{SP}_{\mathrm{h}}$ round 1

$\mathrm{SP}_{\mathrm{h} \text { target round } 2}$

$\mathrm{SP}_{\mathrm{h} \text { round } 2} \quad$ Hood static pressure after round two in inches water gage.

$\rho_{\mathrm{i}} \quad$ Density of the air in branch $\mathrm{i}$ in pounds per cubic foot.

$\rho_{\text {fan }}$

$\mathrm{F}_{\text {order }}$

$\mathrm{SP}_{\text {fan }}$

Airflow in cubic feet per minute (cfm).

Velocity of the air in feet per min.

Cross sectional area of the duct.

Density factor.

Value to which the practitioner adjusts the airflow. in $\mathrm{cfm}$.

Airflow through the branch in cubic feet per minute (cfm).

Airflow at the fan in cubic feet per minute (cfm).

Hood static pressure in inches water gage. inches water gage. in inches water gage.

Hood static pressure after round one in inches water gage. in inches water gage.

Density of the air at the fan in pounds per cubic foot.
The desired airflow through the ducts in cubic feet per minute.

Value before balancing when all dampers are completely open.

Airflow in branch (i) before balancing when all dampers are completely open

Actual airflow after balancing in cubic feet per minute (cfm).

Airflow desired in branch (i) after balancing in cubic feet per minute (cfm).

Airflow to which the balancing practitioner must adjust in cubic feet per minute.

Airflow to which the balancing practitioner must adjust in branch (i) in cfm.

Airflow at the fan before balancing when all dampers are completely open in cfm.

Airflow at the fan desired after balancing in cubic feet per minute.

Hood static pressure before balancing when all dampers are completely open in

Hood static pressure desired after balancing in inches water gage.

Hood static pressure to which the balancing practitioner must adjust in round one

Hood static pressure to which the balancing practitioner must adjust in round two

Order-specific modification factors used when calculating $\mathrm{SP}_{\mathrm{h}}$ target round 1 .

Static pressure of the fan in inches water gauge. 


\section{Chapter 1: Introduction}

A ventilation system is necessary to control workers' exposure to airborne hazardous contaminants. To be effective, a ventilation design system must provide a specified minimum airflow for each hood, each of which is connected by a "branch" duct to the rest of the duct system. If the airflow is too low, the hood may become ineffective in controlling contaminants, and the air velocity in the branch duct may fall to the point that particulates will fall to the bottom of the duct, eventually leading to blockages.

Because of poor system design or changing air flow requirements in many systems, some of the ducts receive insufficient airflows. In the same system, other hoods may receive an airflow that is higher than needed, a costly waste. Clearly, it would be desirable to shift airflows from hoods with unnecessarily high airflows to those with insufficient airflows. That shifting is called balancing the system airflows. Ideally, a system would have exactly the flow needed for each branch duct, thus assuring adequate performance

while otherwise minimizing operating costs. As pointed out by Jorgensen (1983), excessive airflows waste energy, increase operational costs, and increase noise levels in the work place. Hence, balancing a ventilation system is actually an optimization of the system's performance.

There are two general methods that are used to balance a ventilation system. One is to balance the system by design and the other is to balance it using dampers to add resistance to the airflow. The more preferred method is balancing the ventilation system by design (ACGIH, 2005). This is mainly done by manipulating duct sizes and other components so pressures at the junctions are almost equal at the desired airflow distribution. The choice of duct diameter, duct length, roughness, number, and type of elbows influence the static pressure loss of the branch (Besant and Asiedu, 2000; Jorgensen, 1983). This method is appropriate for designing a new system but is of limited use when an existing system must be balanced to meet different airflow requirements. If branches are added or removed or the duct layout changes in a substantial way, the distribution of airflows will shift substantially, reducing the airflow to some of the original branch ducts and increasing it in others. Hence, to change the distribution of an installed system without using dampers, new components with different resistances must be added 
or duct diameters must be substituted (Guffey and Hickey, 1983). Clearly, such changes can be costly, not only due to materials and labor, but also due to disruptions in production.

The alternative to re-building the system is to employ dampers, which are ventilation devices designed to adjust airflows in a duct system (SMACNA, 1993). There are many types of dampers, such as butterfly dampers; multi-blade, opposed blade, and parallel blade dampers; and splitter and shutter dampers (Haines, 1988). Most dampers are not suitable for adjusting airflows in branch ducts. Butterfly dampers can be used in branches and resemble flue dampers found in residential chimneys. Their construction makes them highly vulnerable to plugging from particulates, rags, and other solid and airborne materials. Multi-blade dampers are used in larger HVAC systems where different mixes of outside air are needed depending on whether heating or cooling is desired. They also are highly vulnerable to getting clogged (Hanes, 1988). Splitter dampers are used in "Y" junctions to block airflow from one branch but are encouraged in favour of dampers in each branch. Shutter dampers are commonly used for control of smoke, fire, and hot gases at points where ductwork passes through one wall into another area. They are either open or fully closed, making them unsuitable for balancing duct systems.

The most common type of damper used in industry (and therefore in this study) is the simple slide-gate type (see Figure 1). The slide-gate, also called blast-gate is completely out of the air stream when open and effectively seals the branch when completely shut (Haines, 1988). 

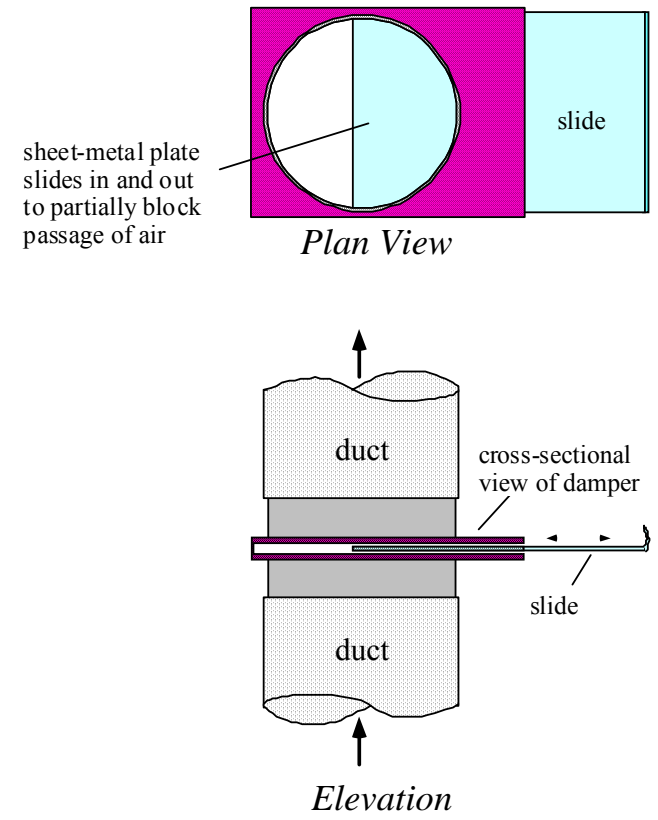

Figure 1. Slide Gate Damper Similar to Those Used in This Study (Guffey, 2005).

These dampers redistribute the air in the ventilation system by obstructing the airflow to a degree the user can vary. As the damper is inserted, the opening becomes smaller, thus increasing the resistance to the airflow. As was demonstrated by Guffey (1993), adding resistance to a branch shifts airflow from it to other branches. This resistance also adds to the total system resistance. Since the fan airflow varies inversely with system resistance, inserting a damper somewhat reduces the total airflow the fan provides to the branches (Guffey, 1993).

Although it is clear that dampers can be adjusted to change the distribution of airflows in a system, finding the appropriate adjustment is not easy and dampers do have disadvantages. For example, operators tend to open the dampers on one branch without considering the effect of airflows on other branches. A system that was originally in balance is thus made ineffective by workers changing the damper settings. When dampers are used, plugging is more likely if sticky or stringent contaminants are in the air stream since they are easily caught on dampers. Accumulated debris such as fragments of paper, rags or dust can congest the system or catch on the dampers. This suggests that dampers must be cleaned, thereby incurring maintenance costs. Infrequent or no cleaning of the 
settlement or coating inside the ducts leads to deterioration of the system's performance. Maintenance can be facilitated by using ducts that are held together with clamps and are easily removable. There are many more problems that could be avoided. For example, the pressure required at the fan can be substantially higher if a damper is used to achieve target airflows without changing the speed of the fan. However, if one is willing and able to set the fan speed correctly, the pressure requirements can be reduced by using dampers (Guffey, 1993). This suggests that when balancing a system, it is appropriate to adjust dampers to achieve the right fraction of the total airflow through each branch, and then adjust the fan speed to achieve the correct levels.

\section{Common Method (direct balancing)}

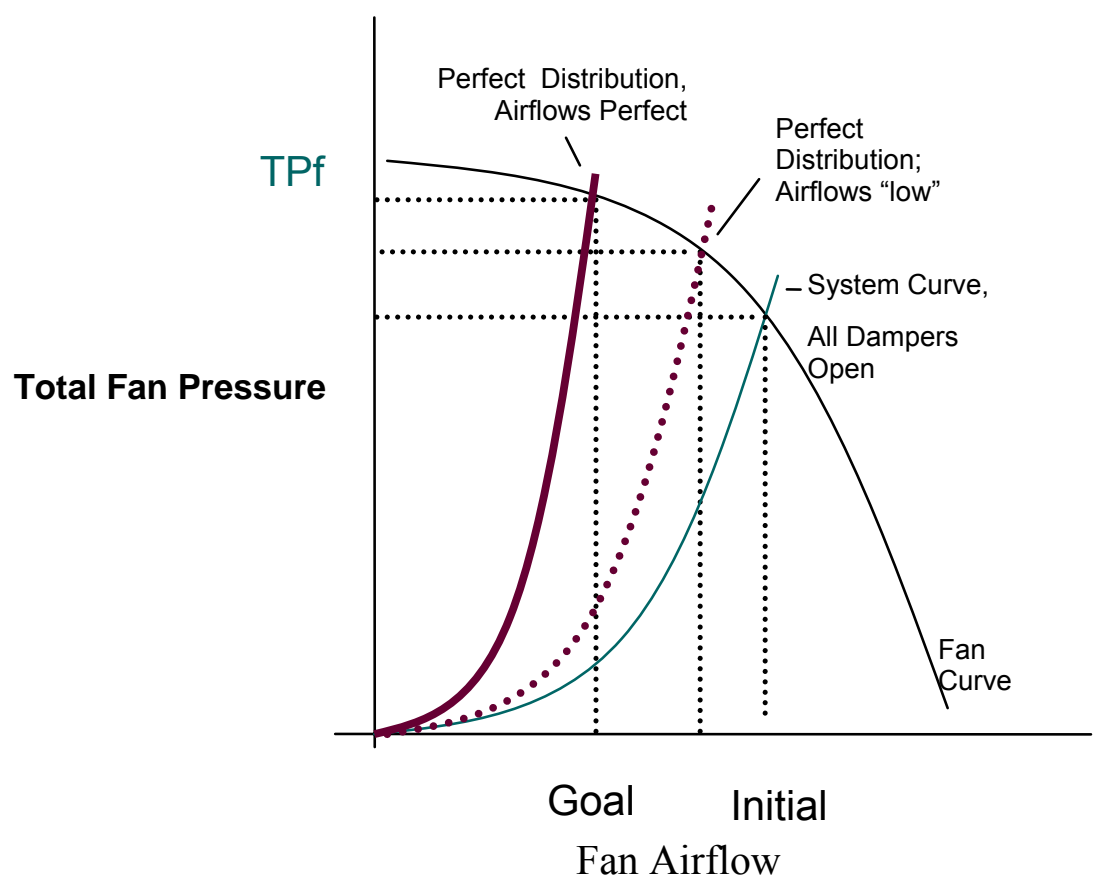

Figure 2. Fan Interactions and Adjustments for the Common Method (Guffey, 2005). 


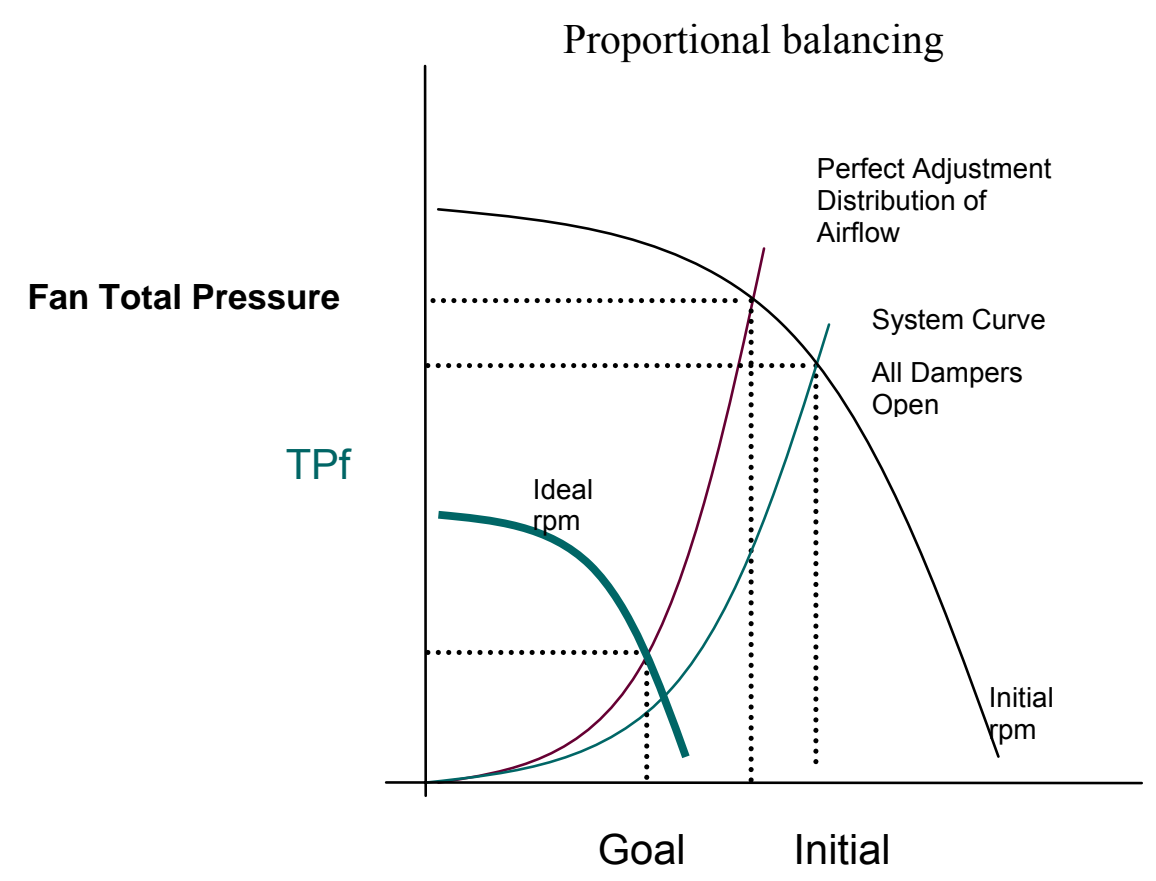

Fan Airflow

Figure 3. Fan Interactions and Adjustments for the Proportional Balancing Method. (Guffey, 2005).

The fan curves at various airflow levels can be observed by plotting a graph between the fan airflow and total fan pressure (Figures 2 and 3). It can be seen that the initial airflow with the dampers open is determined by the intersection of the fan curve and the system curve at that fan rotation rate. As shown (Figure 2) for the common Method, if the system is adjusted, to achieve certain target airflow, dampers are used. They not only achieve the desired relative distribution but also "choke the fan down" to the desired total airflow. If dampers are adjusted to have the right fraction of the total airflow through each branch (Figure 3, perfect distribution, high airflow curve) and the fan speed is adjusted to achieve the desired levels of airflows; the pressure in the system can be much lower than that could be observed in the common method (Figure 2).

Knowing the right damper insertion depth to achieve a good balancing is yet another issue. One way is to measure the airflow each time. Errors in determining the 
airflow from measurements would certainly affect the efficacy of balancing efforts. The most accurate and reliable method is a so-called Pitot traverse (ACGIH, 2005) in which velocity pressures are measured at specified distances across a diameter of the duct. The errors due to Pitot traverses vary with the uniformity of the airflow at that location, which is determined by the presence or absence of disturbances upstream of the measurement location. Guffey and Booth (1999) demonstrated experimentally that airflows can be determined with errors of less than 3 percent virtually every time if disturbances are at least seven duct diameters (7D) distance upstream or more. Even at very close distances (e.g., 3D), errors are typically less than 5 percent.

However, full Pitot traverses are time-consuming, so it is more likely that practitioners actually rely on a well-known shortcut. When a measurement in a branch equals the goal, the probability that the true value exceeds the goal is $50 \%$. If the airflow measurement reads less than the goal, the true airflow has less than $50 \%$ chance of meeting or exceeding the goal. The ideal method for industrial exhaust ventilation systems would be effective and easy to use. It would necessitate very few rounds of adjustment to bring the system into perfect balance. After balancing, the system has the correct distribution of airflow in each branch. At least one damper remains completely open to keep at minimum the losses in system operation and maximize operational efficiency. The ideal method has rational and easily obtainable goals to direct the practitioner and eliminate confusion. These goals are independent of the fan speed. Even if the airflows are incorrect after balancing, the correct proportion of airflow exists in each branch and only the fan needs adjustment. This means that a system can be balanced before its proper fan is installed. Finally, the time and effort the practitioner invests is minimal.

\subsection{Purpose of the Study}

This project was intended to experimentally determine the efficacy of one of the most common methods of balancing exhaust ventilation systems (here called the common method) on a full-sized ventilation system. The results are compared to the efficacy found for the "Target Hood Static Pressure" method by Dodrill (2004). 


\subsection{Methodology}

The following methodology is proposed to be adopted to achieve the goals of the study:

1. A challenging airflow distribution will be selected on a full-sized ventilation system.

2. The airflow through each branch will be measured by conducting a full Pitot traverse.

3. Three different goal airflows will be selected. The target centerline velocity pressures will be calculated for the goal airflows. Centerline velocity pressure is the velocity measured at the center of the duct cross-section. It is used to estimate the average velocity on the assumption that ratio of the average velocity to the centerline velocity is equal to 0.9 (ASHRAE, 2005). This ratio is also called the pipefactor.

4. The damper in each branch will be adjusted until the target centerline velocity is met. However, as a damper in one branch is adjusted, the airflow in other branches may change. Thus, dampers in the branches would be adjusted once again.

5. At the end of two complete rounds of damper adjustments, the final airflow in each branch will be measured.

6. A statistical analysis will be performed to determine the effect of branch number, duct diameter, and airflow levels on the pipefactors.

7. The percent excess airflow through the system will be calculated so as to determine the efficacy of this method.

8. The efficacy of the common method will be compared to the efficacy of the $\mathrm{SP}_{\mathrm{h}}$ goal ratio method. 


\section{Chapter 2. Literature Review}

A search of literature was conducted to determine what balancing methods have been proposed and what experimentation has shown about their effectiveness. Despite a diligent search, no published studies were found that evaluated the effectiveness of "official" ventilation system balancing methods as described in ventilation texts. As will be discussed, two methods not listed in ventilation texts, but described in the literature, have also been tested under laboratory conditions and are discussed in 2.1.

\subsection{Sheet Metal and Air Conditioning Contractors' National Association (SMACNA) Methods.}

The Sheet Metal and Air Conditioning Contractors' National Association (SMACNA, 1993) describes two main methods, the "stepwise method" and the "proportional balancing ratio" method. The SMACNA methods are intended for supply air systems, not exhaust ventilation systems. Supply air systems are very different from exhaust systems in design goals and methods. There is no evidence available to show whether methods that are effective for supply air systems would be effective for exhaust systems or vice-versa.

In the SMACNA stepwise method (see Appendix 1 for details) a Pitot traverse is conducted on all the main branches to determine the air distribution. The branches that have an airflow that exceeds the target are identified. The static pressure is measured at a point downstream of the balancing damper. The damper of the branch having the highest airflow is adjusted until its static pressure comes down to a new level determined by the following equation:

$$
\frac{\mathrm{SP}_{2}}{\mathrm{SP}_{1}}=\left(\frac{\mathrm{Q}_{2}}{\mathrm{Q}_{1}}\right)^{2}
$$


where,

$\mathrm{SP}_{2}$ is the desired new static pressure and $\mathrm{SP}_{1}$ is the existing static pressure measured in inches water gauge.

$\mathrm{Q}_{2}$ is the new airflow and $\mathrm{Q}_{1}$ is the existing airflow measured in cubic feet per minutes. This procedure is repeated for all the branches having a high airflow to complete the first round of adjustments. Once this is done the airflow in the branches that initially had a low airflow would have increased. The static pressure in all the branches is measured once again. The above mentioned procedure is repeated once again starting with the branch having the highest static pressure, completing the second round of adjustments. SMACNA states that two rounds of adjustments are generally sufficient to achieve a good balance, but a final round of adjustment may sometimes be necessary to fine tune the system. A final adjustment is made to the fan speed, if necessary.

The proportional balancing or ratio method (see Appendix 1) requires more mathematical operations. At first, all the dampers of the ducts are opened completely and the air flow measurements are taken $\left(\mathrm{Q}_{\mathrm{m}}\right)$. The desired airflow is labeled as $\mathrm{Q}_{\mathrm{d}}$. The percentage of airflow through each outlet is calculated, which is the ratio of $\left[\left(Q_{m} / Q_{d}\right) \times 100\right]$. This percentage of airflow is calculated for each branch and is labeled in ascending order. The balancing is done in the following steps: In the first step the damper for the branch with the lowest ratio is selected and is left completely open. The average $Q_{m}$ for this branch and the next branch in the ascending order is calculated. The damper for the second branch is adjusted to the average $Q_{m}$ that is calculated. The air pressure in this duct is then verified by measurement so that the two ducts are in balance. In the second step, the next branch in the ascending order is selected. The average $Q_{m}$ for this branch and the previous two branches are calculated. The damper for this branch is adjusted until this average $Q_{m}$ is reached. The air flow in the previously adjusted ducts increases and the three branches are in balance. This procedure is continued and the remaining branches are proportionally balanced. Upon completion of the proportional balancing, all the branches are re-measured. If the $Q_{m}$ is less than the $Q_{d}$, then the speed of the fan is increased so that all the branches receive the necessary airflows.

The author failed to find any published experimental research of the accuracy or 
efficiency (e.g., number of adjustments required to achieve an acceptable set of deviations from target values) for either SMACNA method.

\subsection{The American Society of Heating, Refrigerating, and Air- Conditioning Engineers (ASHRAE) Method.}

The American Society of Heating, Refrigerating, and Air-Conditioning Engineers (ASHRAE, 2005) states that "Two pressure balancing methods can be considered when designing industrial exhaust systems. One method uses balancing devices (e.g. dampers, blast gates) to obtain the desired airflow through each hood. The other approach balances the system by adding resistance to the ductwork (i.e. changing duct work, selecting different fittings, and increasing airflow).” ASHRAE does not state how the target values are obtained, nor does it explain how the dampers must be adjusted. In describing the method, ASHRAE did not refer to any literature.

\subsection{The American Conference of Governmental Industrial Hygienists (ACGIH).}

The American Conference of Governmental Industrial Hygienists (ACGIH, 2005) is a widely distributed manual for ventilation design. However, it has little to say about balancing methods. The ACGIH text lists advantages and disadvantages in using dampers. It notes that there are two types of methods to achieve a proper balance, namely "balancing by design" and balancing, which they call the "blast gate/orifice plate method." For the former, ACGIH states that "achievement of the desired airflow (a balanced system) is achieved without the use of blast gates or orifice plates." A balance is achieved during design by proper selection of system components such that resistances produce the desired distribution. If the distribution must be changed, it is done by substitution of ducts, elbows, etc.

For balancing with dampers, ACGIH states that:

"Blast gates must be adjusted after installation in order to achieve the desired airflow at each hood. At each junction, the flow rates of two joining ducts are achieved by blast gate adjustment that results in the desired static pressure balance."

ACGIH gives no guidance on how to actually adjust the dampers. 


\subsection{Guffey Pressure Ratio Method}

Guffey (1993) proposed a radically different method. In this method the dampers of a system initially are completely open. The baseline measurements of the $\mathrm{SP}_{\mathrm{h}}$ (hood static pressure) and $\mathrm{SP}_{\text {end }}$ (SP measured just upstream of the next downstream junction fitting) are taken. These are used to predict the final values of the same variables. These computations are very complex, making the method impractical without custom software to do the computations (e.g., Heavent, 2003). Geiger (1997) found the above method to be extremely accurate with one round of adjustment in an experimental duct system (a mean error of $2.1 \%)$.

\subsection{Guffey “SP ${ }_{h}$ Goal Ratio” Method}

A less mathematically intense method was proposed more recently by Guffey (2004). This method uses hood static pressure $\left(\mathrm{SP}_{\mathrm{h}}\right)$ readings to balance the system that is somewhat similar to the SMACNA "Stepwise" method. However this method proposes a different sequence for balancing and provides a much more sophisticated method of selecting a target pressure.

To determine the sequence for balancing, each branch's airflow ratio is determined using the equation

$$
\mathrm{Q}_{\text {ratio }}=\mathrm{Q}_{\text {original }} / \mathrm{Q}_{\text {goal }}
$$

The higher the ratio, the greater the difference is between the airflows before and after balancing. A damper adjustment on a branch with a higher airflow ratio should have more impact on the airflow distribution through the entire system than a damper adjustment on a branch with a lower airflow ratio. For this reason, the higher the airflow ratio of a branch, the greater its priority for balancing in order that the greatest impact on balance is settled early in the balancing round. Thus the order is the rank position, decreasing with increasing value of $Q_{\text {original(i) }} / Q_{\text {goal(i) }}$.

SMACNA does not specify which static pressure to employ; Guffey specifies hood static pressures on the basis that they are convenient to measure and are highly correlated to the square of airflow (McLoone, Guffey, and Curran, 1993). If the measurement location is 
upstream of dampers, the relationship between $\mathrm{SP}_{\mathrm{h}}$ and airflow is unaffected by damper adjustments (Guffey, 1993).

The method also includes two other innovations. The first is an attempt to estimate how the fan airflow will change as the dampers are inserted. The second is an attempt to estimate the effect of the order of adjustment on the value of $\mathrm{SP}_{\mathrm{h}}$ that should exist after a correct adjustment. The target hood static pressure for the first round, $\mathrm{SP}_{\mathrm{hTi}}$, for each branch duct is computed from:

$$
\begin{aligned}
& \mathrm{SP}_{\mathrm{hTi}}=\mathrm{F}_{\mathrm{i}} \times \mathrm{SP}_{\mathrm{ho}} \times\left(\mathrm{Q}_{\mathrm{goal}} / \mathrm{Q}_{\mathrm{o}}\right)^{2} \times\left(\mathrm{Qfan}_{\mathrm{o}} / \mathrm{Qfan}_{\mathrm{goal}}\right)^{2} \\
& \text { where } \\
& \mathrm{Q}_{\mathrm{goal}}=\text { desired final value of airflow for this branch in cfm. } \\
& \mathrm{Q}_{\mathrm{o}}=\text { value of airflow in this branch observed when all dampers were open in cfm. } \\
& \mathrm{Qfan}_{\mathrm{o}}=\text { value of airflow at the fan observed when all dampers were open in cfm. } \\
& \mathrm{Qfan}_{\text {goal }}=\text { sum of desired values for the branches in cfm. } \\
& \mathrm{SP}_{\mathrm{hTi}}=\text { target hood static pressure for round one for a branch (i) duct in inches } \\
& \quad \text { water gauge. } \\
& \mathrm{F}_{\mathrm{i}}=\text { factor based on the branch's rank in its value of } \mathrm{Q}_{\mathrm{o}} / \mathrm{Q}_{\mathrm{goal}} . \\
& \mathrm{i}=1,2, \ldots . . ., \mathrm{n} \quad \text { (n is the number of branches in the system) } \\
& \mathrm{SP}_{\mathrm{ho}}=\text { Initial hood static pressure in inches water gauge. }
\end{aligned}
$$

For the partial (half of all dampers) second round, the dampers are adjusted in the order of the magnitudes (i.e., positive or negative) of their deviations from the ratio median (i.e. the median from each branch's result from the ratio of $\left.\left(\mathrm{SP}_{\mathrm{hTi}} / \mathrm{SP}_{\mathrm{h} \text { goal }}\right)\right)$. Each damper is adjusted until the $\mathrm{SP}_{\mathrm{h}}$ is at the value that would exist at the median ratio:

$$
\mathrm{SP}_{\mathrm{h} 2}=\mathrm{SP}_{\mathrm{h} \text { goal }} \times \mathrm{SP}_{\mathrm{h} \text { ratio median }}
$$

where

$\mathrm{SP}_{\mathrm{h} 2}$ is the hood static pressure at the end of round two in inches water gauge. 
$\mathrm{SP}_{\mathrm{h} \text { goal }}$ is the goal static hood pressure in inches water gauge.

$\mathrm{SP}_{\mathrm{h} \text { ratio median }}$ is the median hood static pressure ratio (i.e. median of $\mathrm{SP}_{\mathrm{hTi}} / \mathrm{SP}_{\mathrm{h} \text { goal }}$ ).

$\mathrm{i}=1,2,3 \ldots \ldots \mathrm{n}$ ( $\mathrm{n}$ is the number of branches in the system).

Dodrill (2004) tested this method on the same apparatus used for this study and found it to be very accurate. A three percent deviation was the largest deviation from the desired percentage of the total flow for any branch.

\subsection{Common Method}

The method that will be investigated for this study is the method referred to as common for this publication. Guffey (2004) states that while so-called "TAB” specialists who primarily balance supply air systems may use SMACNA methods; he believes that the great majority of industrial exhausts systems are balanced by maintenance personnel who use a method described here. Although there are undoubtedly variations in how it is executed, the basic steps are these:

1. Measure current airflow $\left(\mathrm{Q}_{\mathrm{o}}\right)$ for each branch,

2. Decide what the airflow goals $\left(Q_{\text {goal }}\right)$ should be, and

3. Adjust each damper in turn until the measured centerline velocity pressure $\left(\mathrm{V}_{\mathrm{cl}}\right)$ is the following value:

$$
\mathrm{V}_{\mathrm{cl}}=\frac{\mathrm{DF}}{0.81} \times\left(\frac{\mathrm{Q}_{\text {goal }}}{\mathrm{A} \times 4005}\right)^{2}
$$

where,

DF is the density factor,

A is the cross-sectional area of the duct.

4. Since the airflow will increase in every branch as other branches are adjusted, only the last branch will have the correct airflow. Hence, steps one and three must be repeated at least once and typically twice.

5. Measure the final airflows with a full Pitot traverse. 
This method is appealingly simple, but, according to Guffey (2005), it is difficult to execute well. Note that some practitioners may ignore the pipefactor and skip the verification step at the end.

It was not possible to find any experimental evaluation of this method. This study provides an experimental evaluation on a full-scale ventilation system and compares the results to the only published results found for other methods. 


\section{Chapter 3. Apparatus}

This experimental study was performed in the West Virginia University Ventilation and Exposure Assessment Laboratory. The experiments were performed on an exhaust ventilation system (see Figures 4 and 5) constructed of 20-gauge galvanized steel duct work that was manufactured and donated by Nordfab Incorporated (Thomasville, NC). This duct system consisted of seven branches (see Figure 4). These branches were of different combinations of lengths, number of elbows, hood design, and cross-sectional areas (see Table 1) so that the branch resistances were diverse.

Table. 1 Specifications of the Ventilation System Used in the Study

\begin{tabular}{|c|c|c|c|c|c|c|c|c|c|}
\hline \begin{tabular}{|c} 
Branch \\
No \\
\end{tabular} & \begin{tabular}{|c} 
Inner \\
Diameter \\
(inches)
\end{tabular} & Section & \begin{tabular}{|c|} 
No. \\
$90^{\circ}$ \\
Elbows \\
with \\
$5 "$ \\
radius \\
\end{tabular} & $\begin{array}{c}\text { No. } \\
90^{\circ} \\
\text { Elbows } \\
\text { with } \\
7 " \\
\text { radius } \\
\end{array}$ & $\begin{array}{l}\text { No. } 90^{\circ} \\
\text { Elbows } \\
\text { with 8" } \\
\text { radius } \\
\end{array}$ & \begin{tabular}{|c} 
No. 60 \\
Elbows \\
with 7" \\
radius \\
\end{tabular} & $\begin{array}{c}\text { No. 60 } \\
\text { Elbows } \\
\text { with 5" } \\
\text { radius } \\
\end{array}$ & \begin{tabular}{|l} 
Length, \\
inches \\
\end{tabular} & Type of Hood \\
\hline 1 & 4.85 & 1 & & & 1 & 1 & & 116 & Duct \\
\hline 2 & 3.84 & 1 & & 1 & & & 1 & 136.5 & $12^{\prime \prime} \times 6 "$ opening $9 "$ deep \\
\hline 3 & 4.85 & 1 & & & 1 & 1 & & 103 & $12^{\prime \prime} \times 6^{\prime \prime}$ opening $9 "$ deep \\
\hline 4 & 3.84 & 1 & & 1 & & 1 & 1 & 147 & Duct \\
\hline 5 & 3.84 & 1 & & 1 & & & 1 & 133 & $12^{\prime \prime} \times 6 "$ opening $9 "$ deep \\
\hline 6 & 4.85 & 3 & 2 & & & & 1 & 273.5 & Duct \\
\hline 7 & 3.84 & 5 & 2 & 2 & & 2 & 1 & 187 & Duct \\
\hline
\end{tabular}




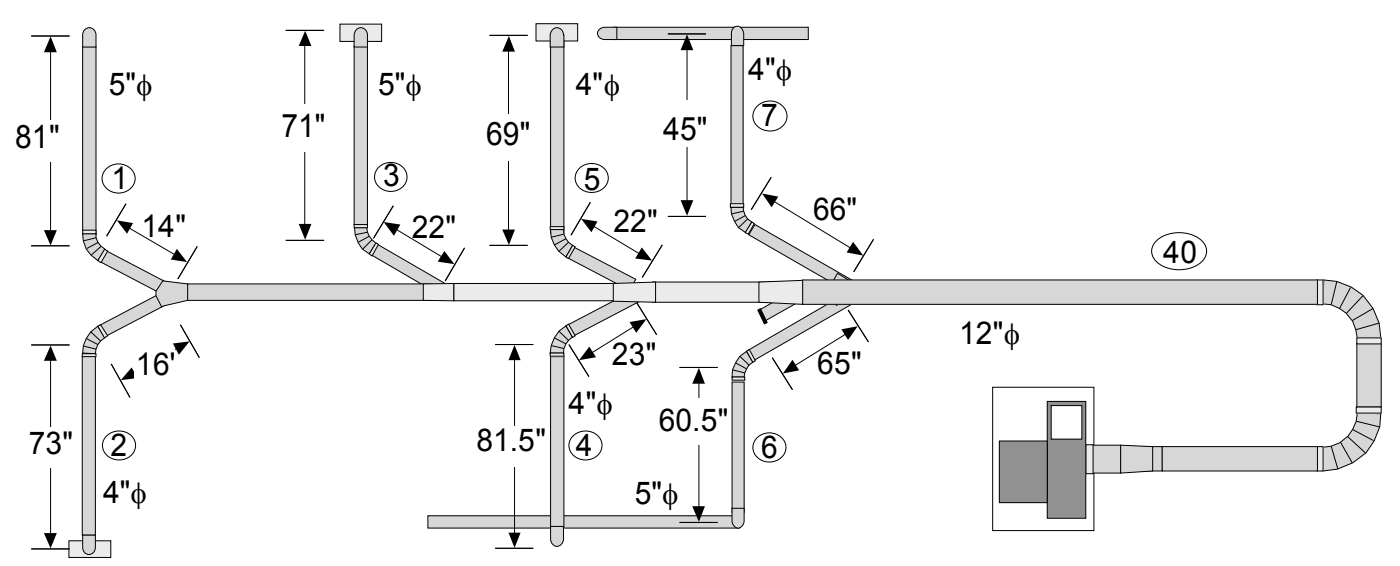

Plan View

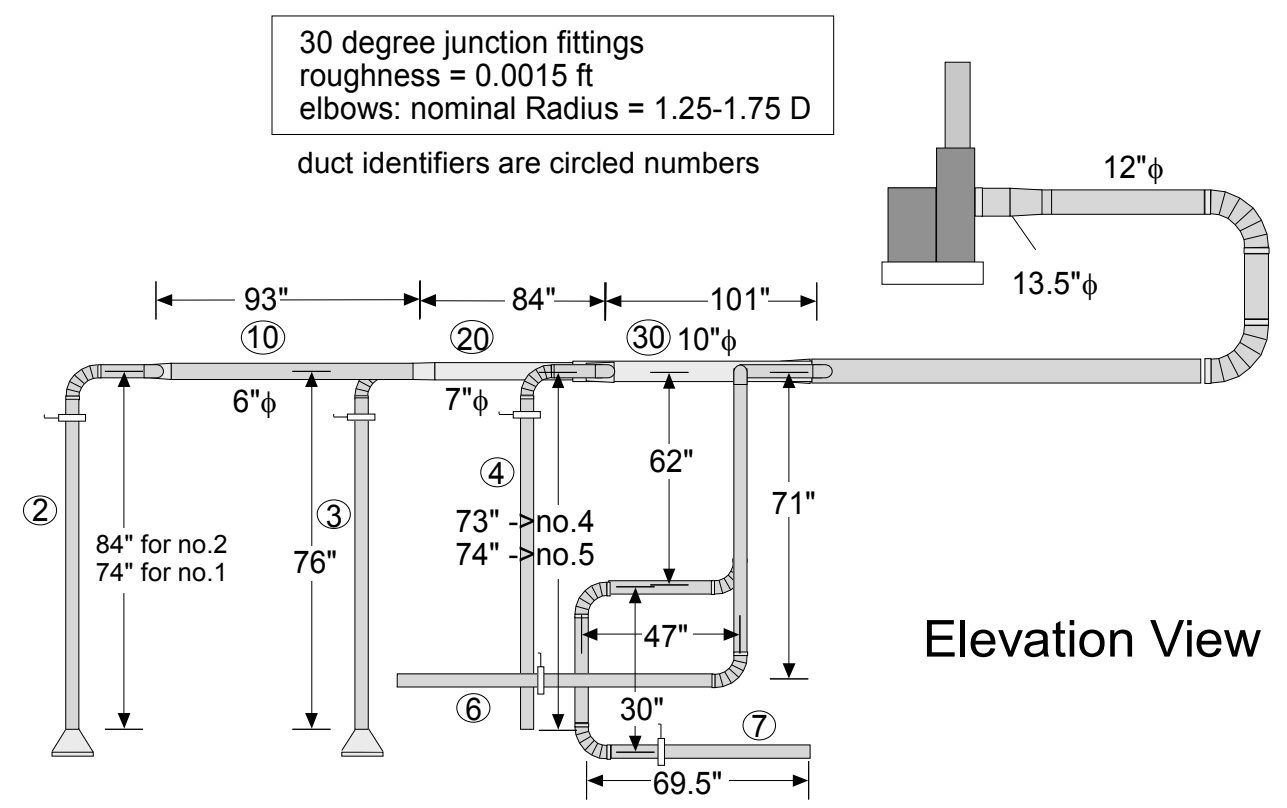

Figure 4. Schematic of the Experimental Ventilation Duct System (Dodrill, 2004). 


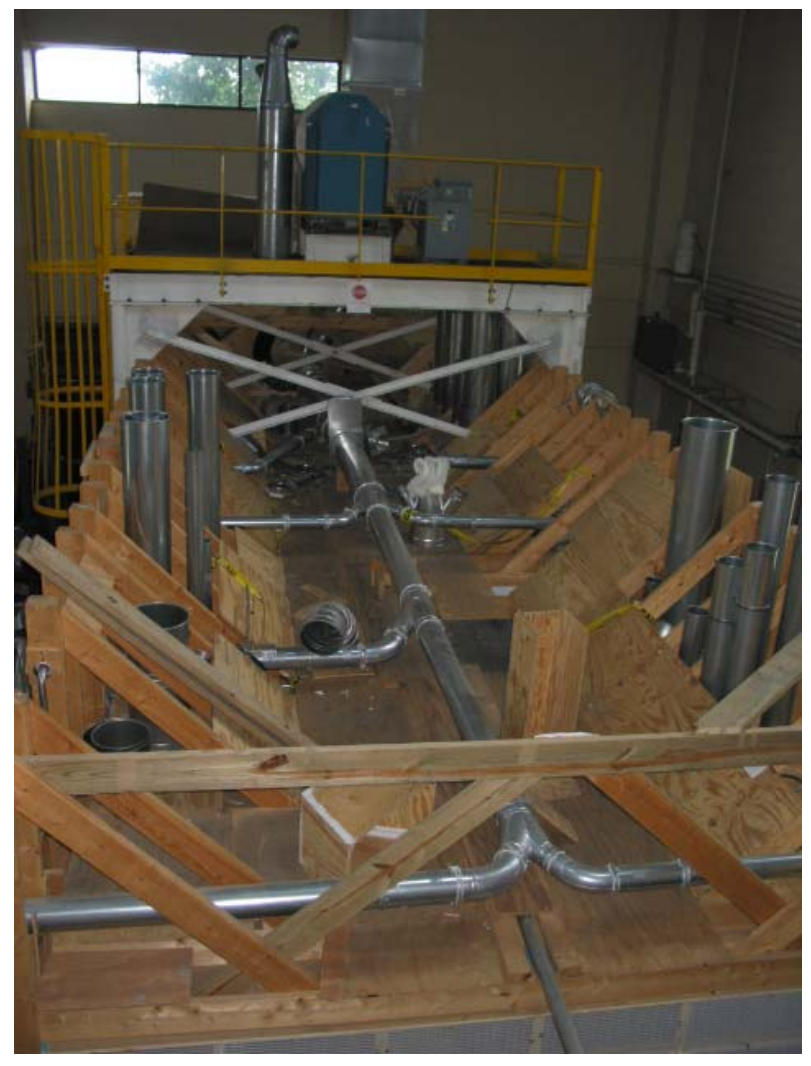

Figure 5. The Ventilation System

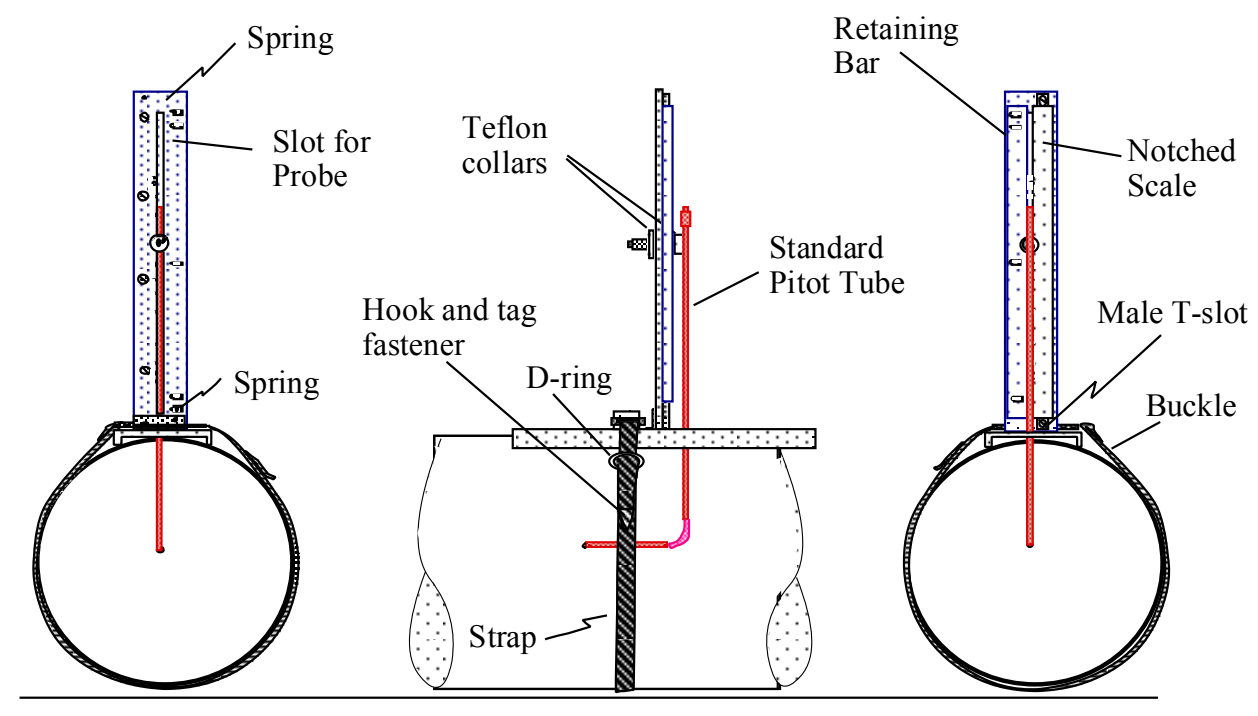

Figure 6. Pitot Traverse Device (ACGIH, 2005).

An Aerovent Fan No. 315BI-SWCB-3435-3 Type SWCB Ser. 8708562-001 was 
used to provide the required air flow through the system. The ducts in the entire system were clamped together. To prevent leaks through these ducts, the claps were shut and sealed with a caulking agent.

The static and velocity pressures were measured using a TSI DP-Calc digital manometer (Model 8702) that was used in conjunction with a standard Dwyer Pitot tube. The investigator used a custom-made device (Guffey, 1990) to hold the Pitot tube in alignment with the duct (see Figure 6). This traverse device had interchangeable scales that were pre-marked to the insertion depths for each duct diameter. Pitot tubes are probes used to conduct pressure to pressure sensor, such as an inclined U-tube or digital manometer. A Pitot tube is actually a tube within a tube. The inner tube is a straight conduit for total pressure while the outer tube conducts static pressure only (Figure 7).

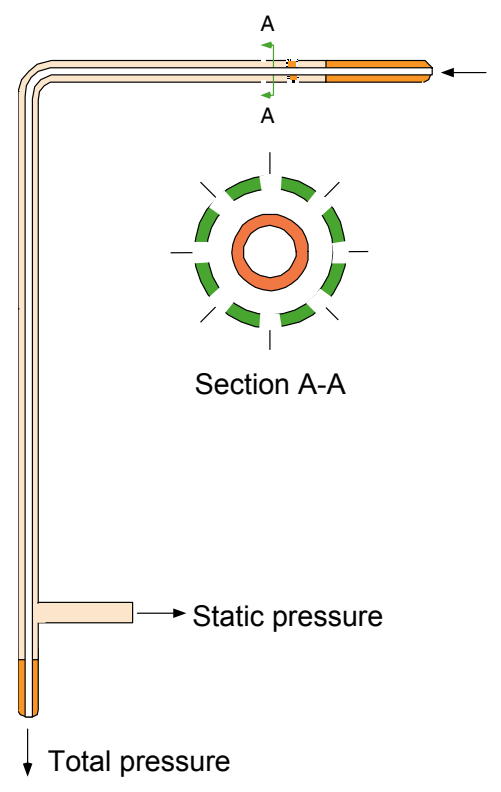

Figure 7. Cross-section of a Pitot tube (ACGIH, 2005). 


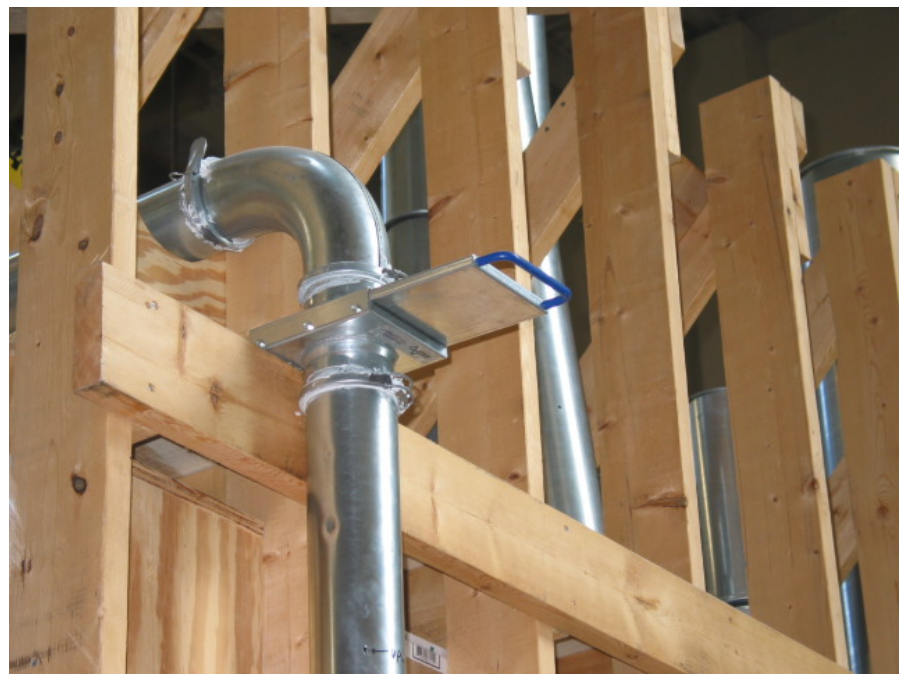

Figure 8. Slide Gate Damper Full Open

\subsection{Dampers}

The slide gate dampers used in this study are similar to the one illustrated in Figure 9. They were manufactured by Nordfab of Thomasville, North Carolina. These dampers are manually operated, are made of galvanized steel with a special sealing device that reduces air loss and friction in operation, and are compact and easy to operate. The leading edge of the slide is concave towards the slide handle. A slide damper that is completely open is shown in Figure 8.

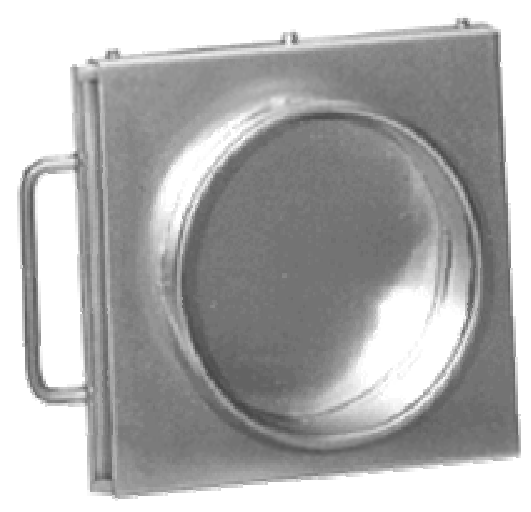

Figure 9. Slide Gate Dampers used for the Study 


\section{Chapter 4. Methods}

This study evaluated the accuracy of the common method typically followed by practitioners (Guffey, 2004), including use of centerline velocity pressures to measure the air flow. The methods include 1) measurement techniques and choice of locations, 2) computation of adjustment parameter values, 3) adjustment of dampers, and 4) computation of results.

\subsection{Pressure and Flow Measurements}

All pressure and flow measurements were carried out using a Pitot tube and a digital manometer. For static pressure readings the digital manometer was set to the average of measurements over five seconds. For velocity pressures, the manometer averaged each reading over one second.

If the total pressure "leg" and the static pressure leg are connected to opposite sides of a manometer, the fluid level is affected by the static pressure equally on both sides, leaving only the effects of velocity pressure. Thus, the velocity pressure can be observed simply by connecting both legs of the Pitot tube to the manometer (Figure 10(c)). Static pressure and velocity pressure should be taken perpendicular to the airflow to avoid errors due to the effects of velocity pressures. For that reason, the Pitot tube is inserted with its stem perpendicular to the duct and its probe inline with the airflow. The static pressure is determined by connecting the static pressure leg to the manometer (Figure 10(b)), and the total pressure is determined by connecting the total pressure leg to the manometer. (Figure $10(\mathrm{a}))$.

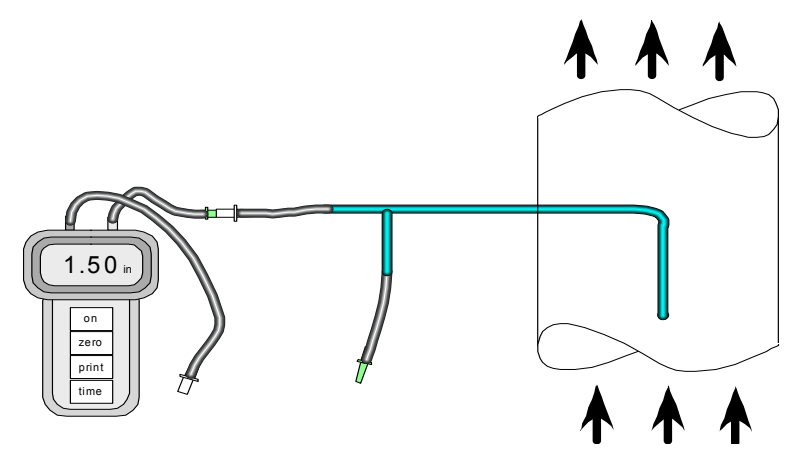

Figure 10.a. Measurements of Total Pressures using a Pitot Tube (Guffey, 2005). 


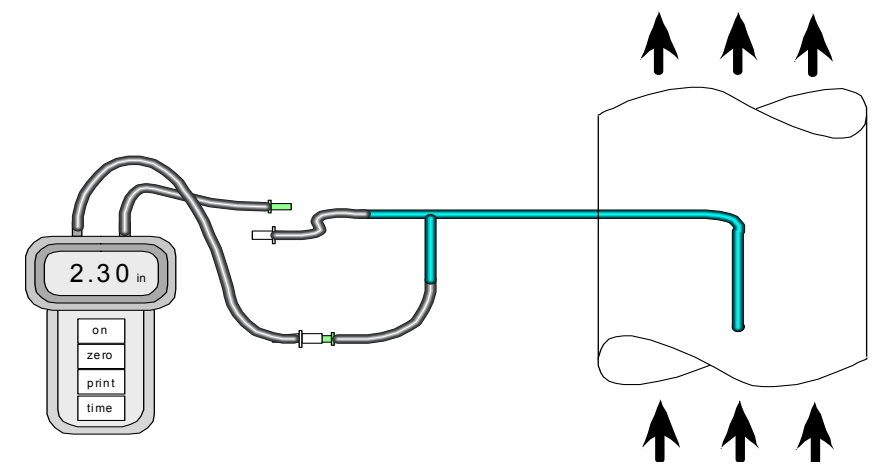

Figure 10.b. Measurements of Static Pressures using a Pitot Tube (Guffey, 2005).

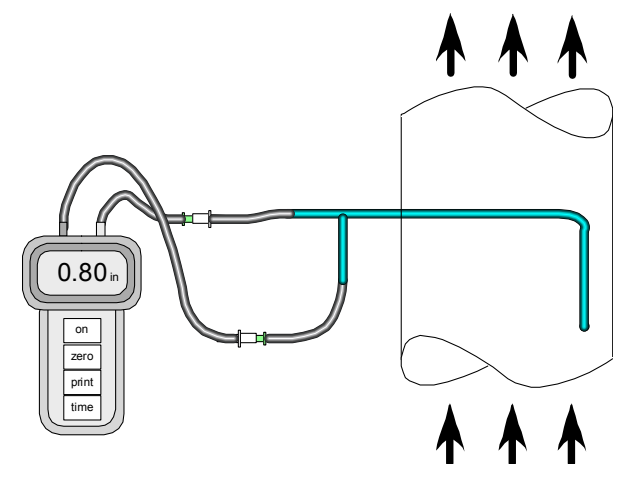

Figure 10.c. Measurements of Velocity Pressures using a Pitot Tube (Guffey, 2005).

The Pitot tube was connected to jigs and holders to position the tube in alignment. Small holes were drilled into the duct. The Pitot tube was inserted into this duct such that its stem was inline with the airflow (in the upstream direction).

Velocity pressures (VP) were measured by conducting a Pitot traverse eight duct diameters from the closest upstream disturbance and at least four duct diameters (4D) from the closest downstream disturbance (see Figure 11). Since values vary with measurement location, estimating average values can be accomplished by taking measurements at representative points across the entire cross section of the duct so that every packet of airflow has the same chance to be sampled. To accomplish this, velocity pressures were measured at each of the 10 recommended insertion depths (ACGIH, 2005). Pitot traverses for two perpendicular diameters were taken at a single cross section for each branch, as recommended by Industrial Ventilation (ACGIH, 2005).

Before commencing with any attempt to balance the dampers, the hood static pressure $\left(\mathrm{SP}_{\mathrm{h}}\right)$ and velocity pressure traverses of each branch were recorded with all dampers 
completely open. The velocity of the airflow could then be calculated from these Pitot traverse readings using equation (6).

$$
\mathrm{V}_{\mathrm{i}}=4005 \times \sqrt{\mathrm{VP}_{\mathrm{i}} / \mathrm{DF}}
$$

where,

VP is the velocity pressures calculated from the Pitot traverse readings in inches water gauge,

$\mathrm{V}$ is velocity of airflow in feet/minute.

$\mathrm{i}=1,2,3 \ldots ., 20$ (insertion depths of the pitot tube), and

DF is the density factor. The density factor is calculated using the formula

$$
\mathrm{DF}=\frac{(\mathrm{Dfalt} \times 293.15)}{(273.15+\mathrm{T})}
$$

where,

$\mathrm{T}$ is the ambient temperature in degrees Centigrade,

Dfalt is the density factor at an altitude of 947 feet (altitude of Morgantown), which is taken to be 0.997 .

The average velocity was calculated using the equation

$$
\mathrm{V}_{\text {avg }}=\sum_{\mathrm{i}=1}^{20} \mathrm{~V}_{\mathrm{i}}
$$

The airflow (Q) in each duct is calculated by multiplying the air velocity (V) by the cross sectional area (A) as shown in the equation

$$
\mathrm{Q}=\mathrm{V} \times \mathrm{A}
$$

The airflow at the fan is the sum of the mass rate of flow of the individual branches divided by the density at the fan. The experiments were conducted in the exposure assessment laboratory. The densities of the air being drawn through each branch were the same as air being drawn from the same room; hence, the Q for the fan was the sum of the airflows of individual branches. 


$$
\mathrm{Q}_{\mathrm{fan}}=\sum_{\mathrm{i}=1}^{7} \mathrm{Q}_{\mathrm{i}}
$$

The average velocity for a given traverse was the average of the values computed from Equation 10. The average velocity pressure $\left(\mathrm{VP}_{\mathrm{avg}}\right)$ was computed from the average velocity (ACGIH, 2005):

$$
\mathrm{VP}_{\mathrm{avg}}=\mathrm{DF} \times\left(\frac{\mathrm{V}_{\mathrm{avg}}}{4005}\right)^{2}
$$

Centerline velocity pressure is the velocity measured at the center of the duct crosssection. It is used to estimate the average velocity on the assumption that $\mathrm{V}_{\mathrm{avg}} / \mathrm{V}_{\mathrm{cl}}=0.9$ (ASHRAE, 2005), hence:

$$
\mathrm{V}_{\mathrm{avg}}=0.9 \times \mathrm{V}_{\mathrm{cl}}
$$

This estimate can be highly inaccurate (Guffey and Booth, 2001) under conditions where the velocity profile in asymmetrical but may be accurate when it is symmetrical.

Static pressures were measured at the duct centerline using the same traverse devices and Pitot tubes. Hood static pressures values $\left(\mathrm{SP}_{\mathrm{h}}\right)$ were measured four duct diameters from the start of the hood (see Figure 11$)$. The system static pressures $\left(\mathrm{SP}_{\text {down }}\right)$ were measured in the submain duct just below of the most downstream branch duct in the system. 


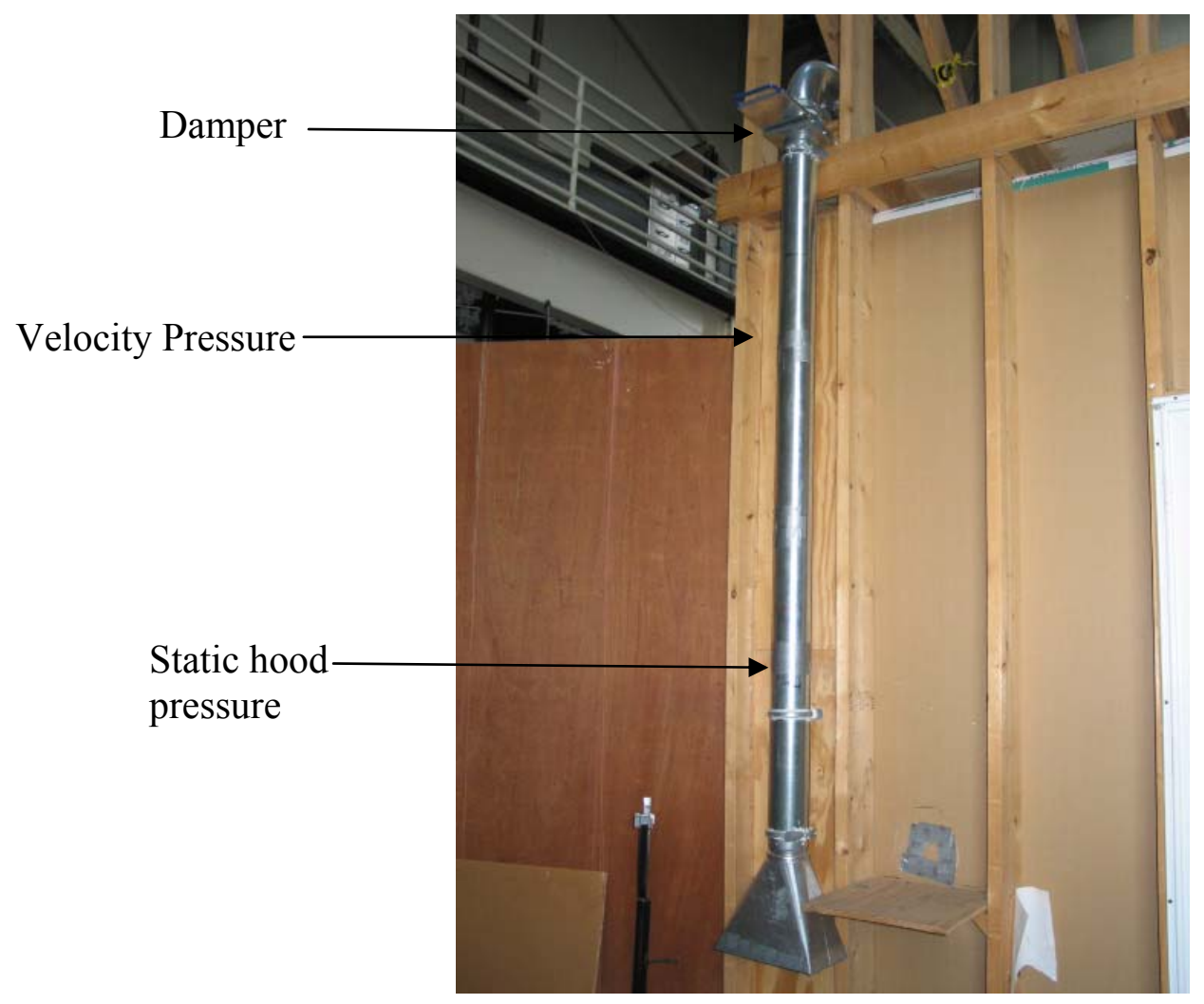

Figure 11. A Hooded Branch (Branch Number Two)

\subsection{Determination of Goal Airflows}

For this study, there was only one desired final, relative distribution of airflows. The relative airflow distribution is the fraction of the total airflow going to each branch. The fractions were selected for each branch in this study to match the earlier study by Dodrill on the same system in order to simplify comparisons of results. The relative distribution of the target airflows is shown in Figure 12. 


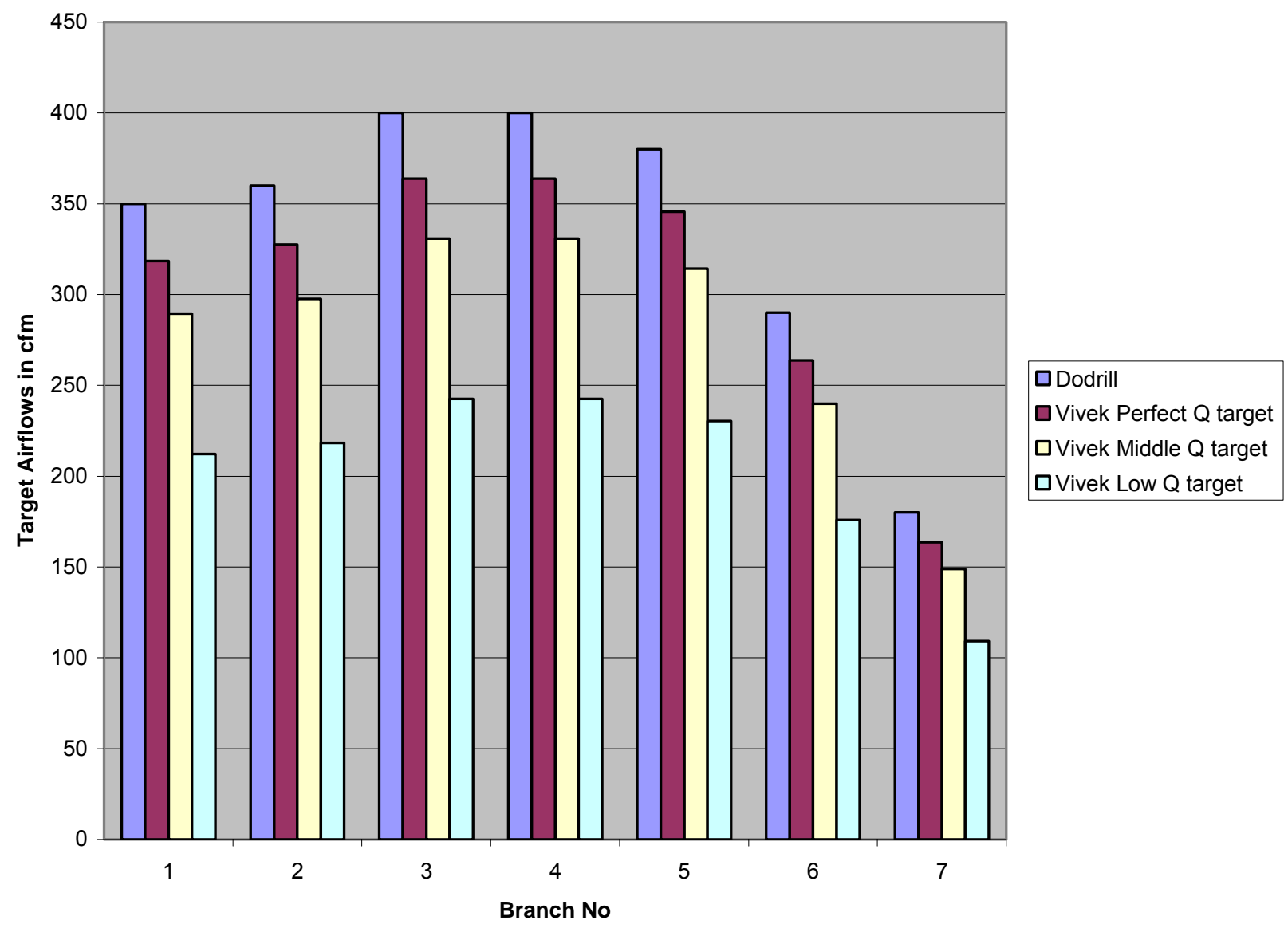

Figure 12. Target Airflows for Each Branch.

For this study, there was only one desired final relative distribution of airflows, but there were three levels of airflow goals: low, moderate and perfect. (Table 2).

Table 2. The Different Target Values for the Branches in cfm.

\begin{tabular}{|c|c|c|c|c|}
\hline Br No. & Q $_{\text {orig }}$ & $\begin{array}{c}\text { Perfect Q } \\
\text { target }\end{array}$ & $\begin{array}{c}\text { Middle Q } \\
\text { target }\end{array}$ & $\begin{array}{c}\text { low Q } \\
\text { target }\end{array}$ \\
\hline 1 & 440.4 & 318.3 & 289.4 & 212.2 \\
\hline 2 & 266.3 & 327.4 & 297.7 & 218.3 \\
\hline 3 & 449.8 & 363.8 & 330.7 & 242.5 \\
\hline 4 & 291.9 & 363.8 & 330.7 & 242.5 \\
\hline 5 & 322.3 & 345.6 & 314.2 & 230.4 \\
\hline 6 & 390.4 & 263.8 & 239.8 & 175.8 \\
\hline 7 & 224.3 & 163.7 & 148.8 & 109.1 \\
\hline System & 2385 & 2147 & 1951 & 1431 \\
\hline
\end{tabular}


The target airflows to which the dampers were adjusted were in the proportions of 66 percent, 90 percent and 100 percent of the perfect case. The perfect case is one for which the fan speed is set such that it is possible for each airflow to equal the desired levels with minimum insertion of dampers. The very low case is when the target air flows are much lower than the perfect target values. The moderate level is when the target air flows are moderately low compared to the perfect airflow. It was assumed that as the dampers choke the fan, the speed of the fan would increase, and this would result in a greater percentage of error in reaching the targets. The author tested to determine if this assumption holds true. Thus the three different types of targets: $V_{c l}$ perfect, $V_{c l}$ moderate, and $V_{c l}$ low were calculated.

\subsection{Calculation of the Goal $V_{c l}$ for Each Branch at Which the System is in Balance}

The most accurate way to determine airflows is to conduct full Pitot traverses and compute values of $\mathrm{Q}$ as discussed above. However, each damper must be adjusted four or more times for each round of adjustment. On the assumption that practitioners would be very unlikely to devote that much time and effort, this study used a shortcut method commonly employed in the field (ACGIH, 2005) using pipe factors.

Now (11) and (12) can be re-arranged to predict the required $\mathrm{V}_{\mathrm{cl}}$ value to obtain a desired airflow. The first step is to express $\mathrm{V}_{\mathrm{cl}}$ in terms of $\mathrm{VP}_{\mathrm{avg}}$

$$
\mathrm{V}_{\mathrm{cl}}=\left(\frac{\mathrm{VP}_{\mathrm{avg}}}{\text { Pipefactor }^{2}}\right)
$$

As discussed earlier, there is a rule of thumb that the pipe factor is typically 0.90 (ACGIH, 2005). Hence, the centerline velocity pressure is equal to

$$
\mathrm{VP}_{\mathrm{cl}}=\left(\frac{\mathrm{VP}_{\mathrm{avg}}}{0.81}\right)
$$

Substituting (11) in (14) we get

$$
\text { Target } \mathrm{VP}_{\mathrm{cl}}=\frac{\mathrm{DF}}{0.81} \times\left(\frac{\mathrm{V}_{\mathrm{avg}}}{4005}\right)^{2}
$$


where,

$\mathrm{V}_{\text {avg }}$ is the average velocity pressure and

DF is the density factor.

Since $\mathrm{V}_{\mathrm{avg}}=\mathrm{Q}_{\mathrm{goal}} / \mathrm{A}$, we have:

$$
\text { Target } \mathrm{VP}_{\mathrm{cl}}=\frac{\mathrm{DF}}{0.81} \times\left(\frac{\mathrm{Q}_{\text {goal }}}{\mathrm{A} \times 4005}\right)^{2}
$$

where,

$\mathrm{A}$ is the cross sectional area of the duct.

As discussed earlier, there were three sets of goals for branch airflows for this study, therefore, there were three sets of target $\mathrm{V}_{\mathrm{cl}}$ values computed from Equation 16 (Table 4).

\subsection{Determination of the Order in Which the Ducts Must be Adjusted}

Before beginning to adjust the dampers, the order in which the branches were chosen was decided as follows. The branches having the greatest amount of airflow through them were chosen first. The branches with a greater cross sectional area would have a greater amount of airflow through them. Hence, ducts having the largest diameter were chosen first. If two or more branches had the same diameter, then the branches were chosen as per the ease of the investigator. This was done so as to replicate the procedure that is followed by a practitioner in the real world (Guffey, 2005). The resistance to airflow increases as the damper in that branch is closed. This also results in an increase in airflow through all other branches. When one adjusts the first damper so that the target velocity pressure is reached and then proceeds to the second branch to adjust its damper, the airflow through the first branch increases. Continuing this will result in most of the branches having excessive flow, forcing additional adjustments. As this procedure of adjusting consumes a great amount of time, the investigator decided to stop after two rounds of adjustments.

As mentioned earlier, the branches having the largest diameter were chosen first. Looking at Table 1, it can be observed that branches one, three, six have a diameter of 4.85 
inches each and branches two, four, five, seven have a diameter of 3.84 inches. Thus, by size and convenience to adjust, the investigator followed the order in which the branches were to be adjusted as shown in Table 3 .

Table 3. The Order in Which the Branches are Adjusted

\begin{tabular}{|c|c|}
\hline $\begin{array}{l}\text { Order in which } \\
\text { the branches } \\
\text { are adjusted }\end{array}$ & Branch No. \\
\hline 1 & 1 \\
\hline 2 & 3 \\
\hline 3 & 6 \\
\hline 4 & 7 \\
\hline 5 & 5 \\
\hline 6 & 2 \\
\hline 7 & 4 \\
\hline
\end{tabular}

\subsection{Damper Adjustments}

To adjust dampers so that airflows shifted from the original to the goal values (Table 4), dampers were adjusted for each branch duct following the common method described earlier. The immediate targets during those adjustments were the centerline velocity $\left(\mathrm{V}_{\mathrm{cl}}\right)$ target values.

The dampers were adjusted in the order shown in Table 3. When adjusting a specific damper, the Pitot tube was first inserted to the centerline notch. The damper was then adjusted till the centerline velocity $\left(\mathrm{V}_{\mathrm{cl}}\right)$ was equal to the target velocity $\left(\mathrm{V}_{\mathrm{cl}}\right.$ goal). Once the target velocity was achieved, the second branch was adjusted.

At the end of the first round of adjustment, the centerline velocity pressures of these individual branches were measured once again. Each value except the last branch adjusted had risen to a higher value. A second round of adjustments was done in the same manner as the first round. After the second round was completed, two 10-point traverses were conducted on each branch to determine the final airflow $\left(\mathrm{Q}_{\text {final }}\right)$ for each branch. This whole 
process was repeated once for each set of goal airflows. The goals levels and their replicates were done in random order.

Table 4. Original, Target and Goal Airflows and Centerline Velocity Target Pressures

(Airflows in $\mathrm{ft}^{3} / \mathrm{minute}$, Hood Static Pressures in inches water gage)

\begin{tabular}{|c|c|c|c|c|c|c|c|c|}
\hline Br No. & Qorig & $\begin{array}{c}\text { Perfect Q } \\
\text { target }\end{array}$ & $\begin{array}{c}\text { Moderate } \\
\text { Q target }\end{array}$ & $\begin{array}{c}\text { Low Q } \\
\text { target }\end{array}$ & $\begin{array}{c}\text { Vcl } \\
\text { Original }\end{array}$ & $\begin{array}{c}\text { Perfect } \\
\text { VPcl } \\
\text { Target }\end{array}$ & $\begin{array}{c}\text { Moderate } \\
\text { VPcl } \\
\text { Target }\end{array}$ & $\begin{array}{c}\text { Low VPcl } \\
\text { Target }\end{array}$ \\
\hline 1 & 440.4 & 318.3 & 289.4 & 212.2 & 0.836 & 0.464 & 0.384 & 0.206 \\
\hline 2 & 266.3 & 327.4 & 297.7 & 218.3 & 0.769 & 1.249 & 1.033 & 0.555 \\
\hline 3 & 449.8 & 363.8 & 330.7 & 242.5 & 0.877 & 0.606 & 0.501 & 0.269 \\
\hline 4 & 291.9 & 363.8 & 330.7 & 242.5 & 1.018 & 1.542 & 1.275 & 0.686 \\
\hline 5 & 322.3 & 345.6 & 314.2 & 230.4 & 1.204 & 1.392 & 1.15 & 0.619 \\
\hline 6 & 390.4 & 263.8 & 239.8 & 175.8 & 0.686 & 0.319 & 0.263 & 0.142 \\
\hline 7 & 224.3 & 163.7 & 148.8 & 109.1 & 0.549 & 0.312 & 0.258 & 0.139 \\
\hline Fan & 2385 & 2147 & 1951 & 1431 & 5.94 & 5.88 & 4.86 & 2.62 \\
\hline
\end{tabular}

\subsection{Determination of Adjustment Effectiveness}

The efficacy of balancing methods were computed using the percentage of excess airflow:

The percentage of excessive airflow for each branch (i), was calculated using the formula

Percentage of excessive air flow for branch $i=\frac{\left[\left(\frac{\mathrm{Q}_{\text {obs i }}}{\text { Fan } \mathrm{Q}_{\text {ratio }}}\right)\right]-\mathrm{Q}_{\text {target } \mathrm{i}}}{\mathrm{Q}_{\text {target } \mathrm{i}}}$

The fan ratio was first calculated (Fan ${ }_{\text {ratio) }}$ using formula:

$$
\mathrm{Q}_{\text {Fan Ratio }}=\text { minimum of } \frac{\mathrm{Q}_{\text {target } \mathrm{i}}}{\mathrm{Q}_{\mathrm{obs} \mathrm{i}}} \quad \text { of all branches. }
$$


where,

$\mathrm{Q}_{\text {target } \mathrm{i}}$ is the target airflow for branch $\mathrm{i}$.

$\mathrm{i}=1,2, \ldots, 7$.

$\mathrm{Q}_{\text {obis i }}$ is the observed airflow of the branch.

Thus the percent of excessive air flow was calculated for the data collected for the common method and the $S P_{h}$ goal ratio method. These values were used as the basis for comparing the efficacy of the two methods. 


\section{Chapter 5. Results and Discussions}

Since the centerline velocity pressures were used to estimate airflows during adjustments, the accuracy of the pipe factors is relevant to understand the results of the study. However, the results of greatest interest in this study were the excess airflow through the system, the most realistic measure of adjustment effectiveness.

As mentioned earlier, a Pitot traverse was conducted with all the dampers open to determine velocity pressures at each insertion depth. The actual velocities were calculated. (Appendix 2, Table 1). The data was then plotted to observe the velocity profile (Figure 13). Points one to ten indicate the insertion depths of the Pitot tube for the first traverse. Points eleven to twenty indicate the insertion depths of Pitot traverse that is conducted perpendicular to the previous traverse. "CL" is the centerline velocity as shown in Figure 13.

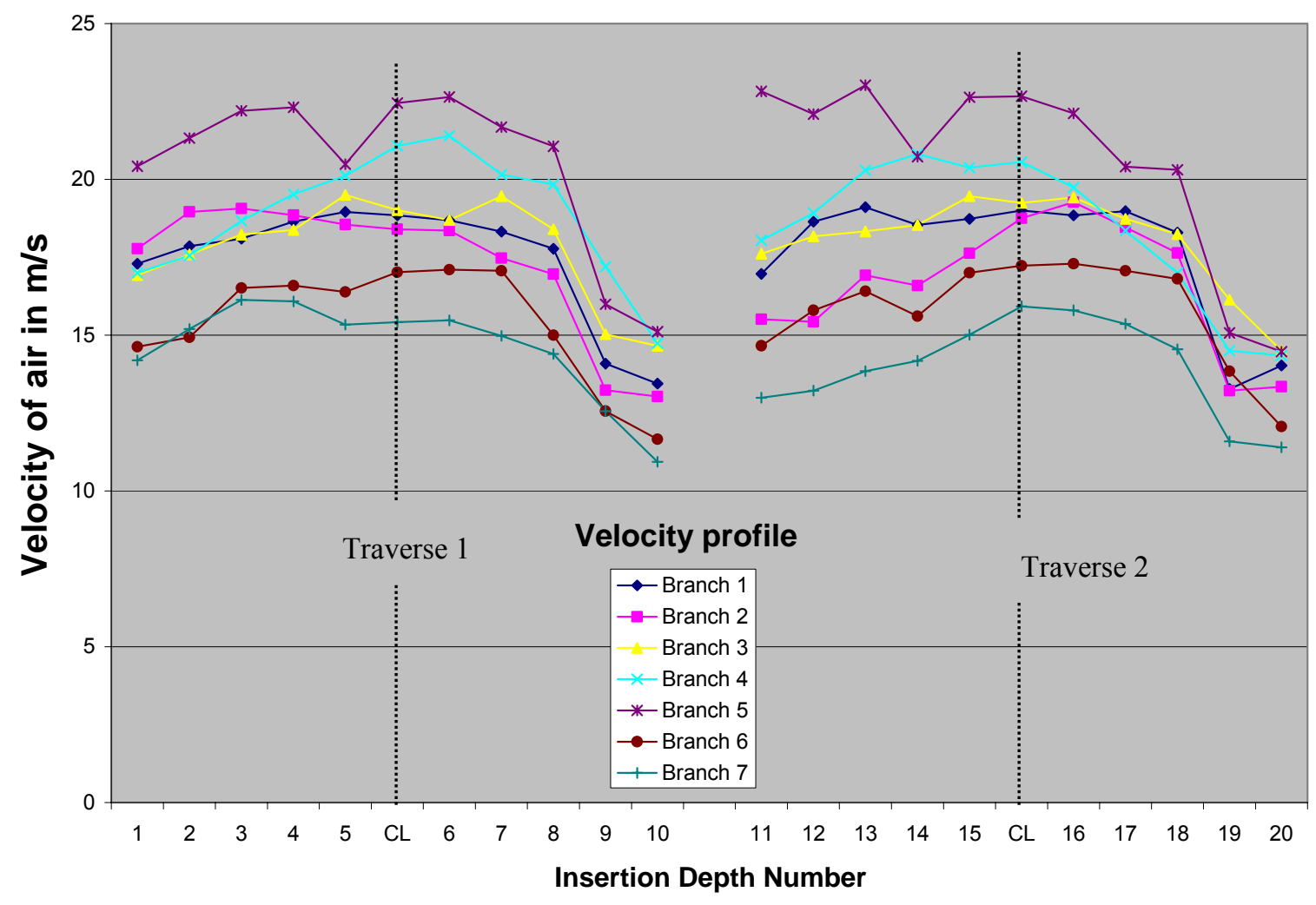

Figure 13. Velocity Profile 
Under these measurement conditions one would expect symmetry in the velocity profile; instead it can be observed that the velocity at the first insertion depth was not equal to the velocity at the last insertion (point ten in Figure 13) depth for the first traverse. Similarly the velocity at the first insertion depth for the traverse perpendicular to the first (point eleven in Figure 13) insertion depth was not equal to the last insertion depth. It is most likely that first and second positions were not actually reached during measurements, probably due to a consistent mistake in installing the Pitot tube holding device. It appears that the Pitot probe was inserted through the center of the slot (see Figure 14) instead of the downstream edge of the slot. If that occurred, then the curve of the Pitot probe where it goes from horizontal to vertical would come up against the inside of the duct, preventing the Pitot tube from being moved completely to the first and second positions. Since the probe is somewhat flexible, it could simply bend the probe out of line with the duct, changing the actual insertion depth slightly. Hence, the first and second positions were actually measured slightly towards the center of the duct.

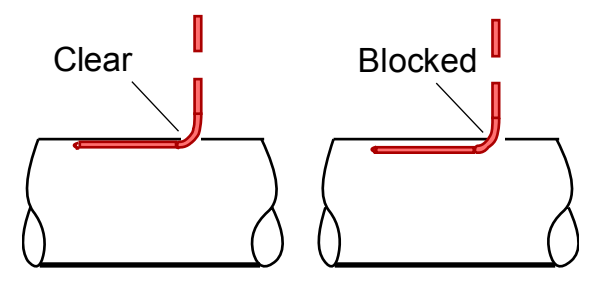

Figure 14. Alignment of the Pitot Tube

\subsection{Study of Flow in the Duct}

In order to investigate the reason for the lack of symmetry, the Reynolds number for the various velocities were calculated. The Reynolds number is calculated using the formula

$$
\mathrm{R}=\frac{\rho \mathrm{VD}}{\mu}
$$

where,

$\mathrm{R}$ is the Reynolds number,

$\mathrm{V}$ is the velocity in $\mathrm{m} / \mathrm{s}$ (Appendix 2 . Table 1 ),

$\mathrm{D}$ is the diameter of the duct in meters. (Diameters taken were 0.123 and 0.097 meters), 
$\mu$ is the viscosity which is taken to be $1.8 \times 10^{-5} \mathrm{~kg} / \mathrm{ms}$ (T.J. Chung, 2002), and $\rho$ is the density of air which is taken to be $1.223 \mathrm{~kg} / \mathrm{m}^{3}$ (T.J. Chung, 2002).

By using these values the Reynolds number for each branch was calculated for each insertion depth number which is shown in the Table 5.

Table 5. Reynolds Number

\begin{tabular}{|c|c|c|c|c|c|c|c|c|c|c|}
\hline & \multicolumn{10}{|c|}{ Insertion depth Number } \\
\hline & \multicolumn{10}{|c|}{} \\
\hline Branch No & $\mathbf{1}$ & $\mathbf{2}$ & $\mathbf{3}$ & $\mathbf{4}$ & $\mathbf{5}$ & $\mathbf{6}$ & $\mathbf{7}$ & $\mathbf{8}$ & $\mathbf{9}$ & $\mathbf{1 0}$ \\
\hline 1 & 146167 & 150941 & 153026 & 157688 & 160250 & 157974 & 154888 & 150240 & 119092 & 113646 \\
\hline 2 & 118289 & 126171 & 126910 & 125502 & 123473 & 122179 & 116296 & 112867 & 88109 & 86718 \\
\hline 3 & 143037 & 148726 & 154107 & 155374 & 164891 & 158070 & 164524 & 155568 & 127061 & 123935 \\
\hline 4 & 113116 & 116857 & 124304 & 129969 & 133938 & 142466 & 134147 & 132039 & 114513 & 98152 \\
\hline 5 & 135948 & 141939 & 147751 & 148509 & 136360 & 150759 & 144292 & 140216 & 106471 & 100599 \\
\hline 6 & 123691 & 126227 & 139621 & 140268 & 138536 & 144611 & 144297 & 126823 & 106236 & 98574 \\
\hline 7 & 94461 & 101155 & 107346 & 107084 & 102076 & 102988 & 99665 & 95838 & 83643 & 72759 \\
\hline
\end{tabular}

The Reynolds number ranged from $7.2 \times 10^{4}$ to $1.6 \times 10^{5}$. The flow of air is considered to be turbulent if its value is greater than 4000 (T.J. Chung, 2002). As these values were greater than 4000 , it can be concluded that the airflows were turbulent.

\subsection{Pipe Factors}

As described in Methods, centerline velocity pressure $\left(\mathrm{VP}_{\mathrm{cl}}\right)$ values were used to make actual adjustments under the commonly held assumption that airflows can be estimated using pipefactors. The pipe factor was assumed to be 0.9 , and the observed values were computed using the equation

$$
\mathrm{PF}=\frac{\mathrm{V}_{\mathrm{avg}}}{\mathrm{V}_{\mathrm{cl}}}
$$




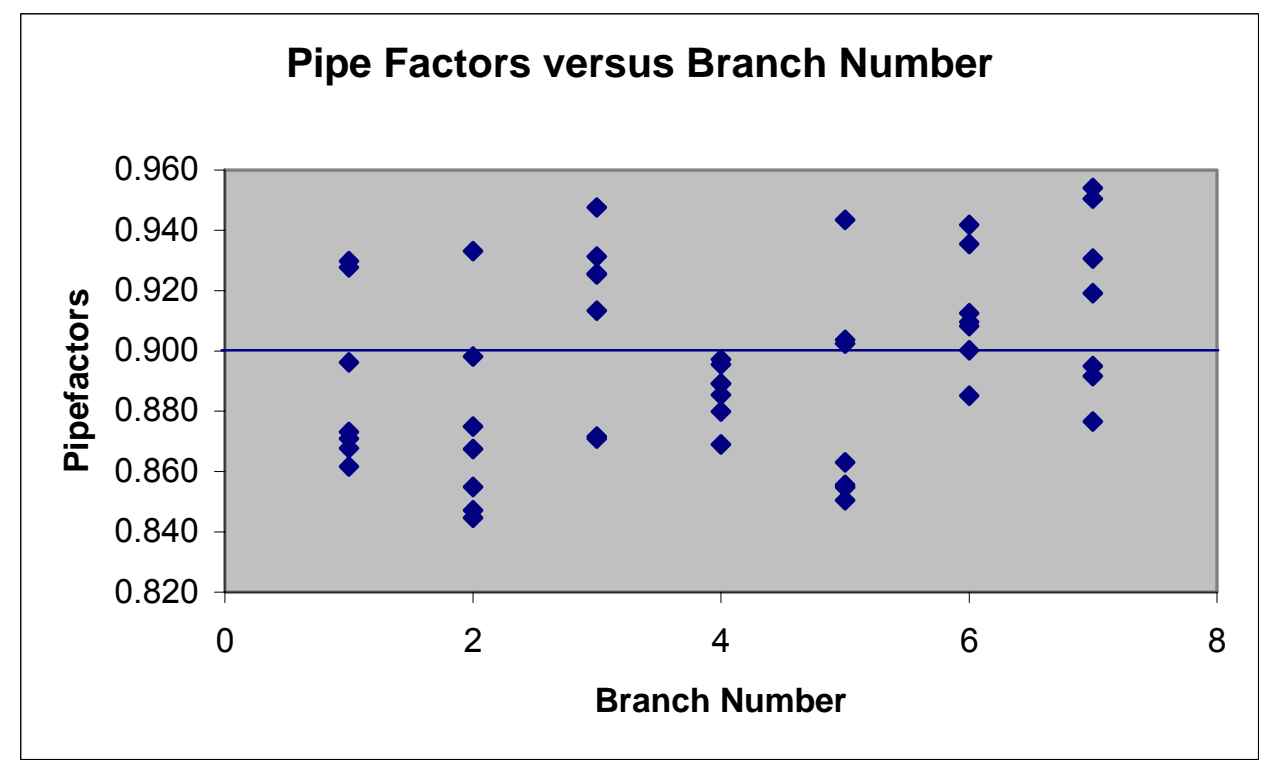

Figure 15. Plot of Pipefactors versus Branch Number

As shown in Figure 15, the observed pipe factors appeared to vary little from branch to branch. The average pipe factor was found to be 0.896 . The median value was found to be 0.889 . All of these values were within six percent of 0.9 . These centerline velocity pressures varied from branch to branch and kept changing as the dampers were adjusted. It follows that versus

$$
\mathrm{V}=\rho \times \sqrt{\mathrm{VP}}
$$

where, $\mathrm{V}$ is the velocity and $\rho$ is the density factor

By substituting (21) in equation (20) we get

$$
\mathrm{PF}=\frac{\rho \times \sqrt{\mathrm{VP}_{\text {avg }}}}{\rho \times \sqrt{\mathrm{VP}_{\mathrm{cl}}}}
$$

Thus, we have

$$
\mathrm{VP}_{\mathrm{avg}}=\mathrm{PF}^{2} \times \mathrm{VP}_{\mathrm{cl}}
$$

The observed values of pipe factors in this study ranged from 0.845 to 0.954 with a 
standard deviation (s) of 0.0388 . The median and average values were 0.889 and 0.896 respectively, which are extremely close to the nominal value of 0.9 . The 95 percent (i.e. $\alpha=0.05$ ) confidence interval for the pipe factors was calculated using the formula where the sample size (n) was 49.

$$
\text { C.I. }=\overline{\mathrm{y}}-\mathrm{t} \alpha / 2 \frac{\mathrm{s}}{\sqrt{\mathrm{n}}} \leq \mu \leq \overline{\mathrm{y}}+\mathrm{t} \alpha / 2 \frac{\mathrm{s}}{\sqrt{\mathrm{n}}}
$$

Thus, C.I. $=0.896-2.03 \frac{0.0388}{\sqrt{49}} \leq \mu \leq 0.896+2.03 \frac{0.0388}{\sqrt{49}}$

95 percent C.I. for the pipe factors (PF) $=0.885<\mu<0.907$.

Therefore, one cannot reject the proposition of the pipefactor to be 0.9 .

A test was conducted to see if the levels of airflow and branch number were significant, taking the pipefactor as the dependant variable. The linear statistical model is stated as shown below.

$$
\mathrm{y}_{\mathrm{ijk}}=\mu+\tau_{\mathrm{i}}+\beta_{\mathrm{j}}+(\tau \beta)_{\mathrm{ij}}+\varepsilon_{\mathrm{ijk}}
$$

where,

$i=1,2,3$ (the levels of airflow),

$\mathrm{j}=1,2 \ldots .7$ (the branch numbers),

$\mathrm{k}=1,2$,

$\mu$ is the overall mean,

$\tau_{\mathrm{i}}$ is the effect of level $\mathrm{i}$ of the airflow,

$\beta_{\mathrm{j}}$ is the effect of level $\mathrm{j}$ of the branch number, and

$\varepsilon_{\mathrm{ijk}}$ is the random error component IID N $\left(0, \sigma^{2}\right)$.

A two way ANOVA was conducted on the data (Appendix 2, Table 8). The results of the ANOVA are shown in Table 6. 
Dependent Variable: Pipefactor

Table 6. Analysis of Variance

\begin{tabular}{|c|c|c|c|c|c|}
\hline Source & df & $\begin{array}{c}\text { Sums of } \\
\text { Squares }\end{array}$ & Mean Square & F-ratio & p \\
\hline Model & 20 & 0.040 & 0.002 & 8.61 & 0.0001 \\
\hline Error & 21 & 0.005 & 0.0002 & & \\
\hline Total & 41 & 0.045 & & & \\
\hline R-Square & Coeff Var & Root MSE & Pipe factor Mean & & \\
\hline 0.891 & 1.713 & 0.015 & 0.892 & & \\
\hline Source & df & Type I SS & Mean Square & F Value & Pr $>$ F \\
\hline Airflow & 2 & 0.004 & 0.002 & 9.6 & 0.0011 \\
\hline Branch & 6 & 0.016 & 0.003 & 11.96 & $<.0001$ \\
\hline Airflow*Branch & 12 & 0.019 & 0.002 & 6.77 & $<.0001$ \\
\hline
\end{tabular}

From the p-values, it can be observed that the levels of airflow were significant $(p=0.0011)$, the different branches were significant $(p<0.0001)$, and the interaction between the airflow and the branch was also significant $(\mathrm{p}<0.0001)$.

An analysis was conducted to test the significance of the different duct diameters. As stated earlier branch numbers one, three, and six were of a diameter of 4.85 inches while branch number two, four, five, and seven were of a diameter 3.85 inches. The different duct diameters were compared using the idea of a "contrast".

In general, a contrast is a linear combination of parameters of the form

$$
\Gamma=\sum_{\mathrm{i}=1}^{\mathrm{a}} \mathrm{c}_{\mathrm{i}} \mu_{\mathrm{i}}
$$

Where the contrast constants $\mathrm{c}_{1}, \mathrm{c}_{2} \ldots . \mathrm{c}_{\mathrm{a}}$ sum to zero (Montgomery, 2001). Thus, the hypotheses can be expressed as shown. 


$$
\begin{aligned}
& \mathrm{H}_{\mathrm{o}}: 1 / 3\left(\mu_{1}+\mu_{3}+\mu_{6}\right)-1 / 4\left(\mu_{2}+\mu_{4}+\mu_{5}+\mu_{7}\right)=0 \\
& \mathrm{H}_{1}: 1 / 3\left(\mu_{1}+\mu_{3}+\mu_{6}\right)-1 / 4\left(\mu_{2}+\mu_{4}+\mu_{5}+\mu_{7}\right) \neq 0
\end{aligned}
$$

The results of the analysis performed on the data (Appendix 2, Table 8) are shown in Table 7 (SAS program shown in Appendix 3).

Dependent variable: Pipefactor

Table 7. Analysis of Duct Diameters

\begin{tabular}{|c|l|c|c|}
\hline Parameter & Error & t Value & $\operatorname{Pr}>|t|$ \\
\hline $\mathrm{H}_{\mathrm{o}}: 1 / 3\left(\mu_{1}+\mu_{3}+\mu_{6}\right)-1 / 4\left(\mu_{2}+\mu_{4}+\mu_{5}+\mu_{7}\right)=0$ & 0.0047 & 3.85 & 0.0009 \\
\hline
\end{tabular}

It can be observed that the difference due to the duct diameter was significant $(p=0.0009)$. Thus, for the above analysis, the duct diameters, branch numbers, and levels of air flow were significant. The error in estimating the airflows using the factor of 0.9 would vary by branch id, contributing to the percentage of excessive airflow. For Pitot traverse measurements under controlled conditions, 90 percent of measurement error falls within three percent of the true value (Guffey and Booth, 1999). Hence, it is likely that the common method could be more precise if the practitioner were willing to make extraordinary number of Pitot traverses in place of $\mathrm{VP}_{\mathrm{cl}}$ measurements.

\subsection{Deviation between Target and Final Airflows for Individual Branches}

Although dampers were adjusted using centerline velocity pressure $\left(\mathrm{VP}_{\mathrm{cl}}\right)$ measurements to estimate airflows during adjustments, the final airflows were determined with full Pitot traverses. As can be seen in Table 9, after completion of the second round of damper adjustments, the levels of airflow in the branches ranged from 91.6 percent to 111 percent of target values, a spread of roughly \pm 10 percent. The average root mean square error was 6.1. 
Table 8. The Ratio of the Target Airflow to the Final Airflow for each Branch

\begin{tabular}{|c|c|c|c|c|c|c|}
\hline \multicolumn{7}{|c|}{$\%\left(Q_{\text {Final }} / Q_{\text {Target }}\right)$ after second round } \\
\hline 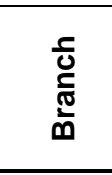 & 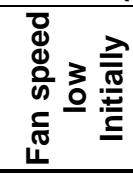 & 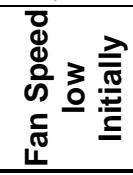 & 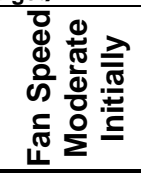 & 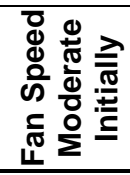 & 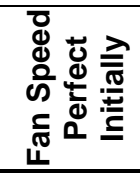 & 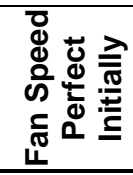 \\
\hline 1 & $102.25 \%$ & $106.56 \%$ & $94.62 \%$ & $92.71 \%$ & $94.34 \%$ & $94.93 \%$ \\
\hline 2 & $98.70 \%$ & $97.30 \%$ & $91.23 \%$ & $91.76 \%$ & $89.24 \%$ & $90.31 \%$ \\
\hline 3 & $106.03 \%$ & $108.36 \%$ & $105.63 \%$ & $106.51 \%$ & $93.81 \%$ & $95.05 \%$ \\
\hline 4 & $97.05 \%$ & $96.86 \%$ & $95.28 \%$ & $94.59 \%$ & $95.47 \%$ & $97.96 \%$ \\
\hline 5 & $109.67 \%$ & $100.73 \%$ & $94.16 \%$ & $91.91 \%$ & $91.41 \%$ & $91.57 \%$ \\
\hline 6 & $100.81 \%$ & $96.33 \%$ & $108.22 \%$ & $107.89 \%$ & $103.26 \%$ & $102.81 \%$ \\
\hline 7 & $98.27 \%$ & $96.25 \%$ & $111.35 \%$ & $108.81 \%$ & $100.77 \%$ & $104.30 \%$ \\
\hline RMSE & $4.61 \%$ & $4.75 \%$ & $7.46 \%$ & $7.59 \%$ & $6.97 \%$ & $5.92 \%$ \\
\hline
\end{tabular}

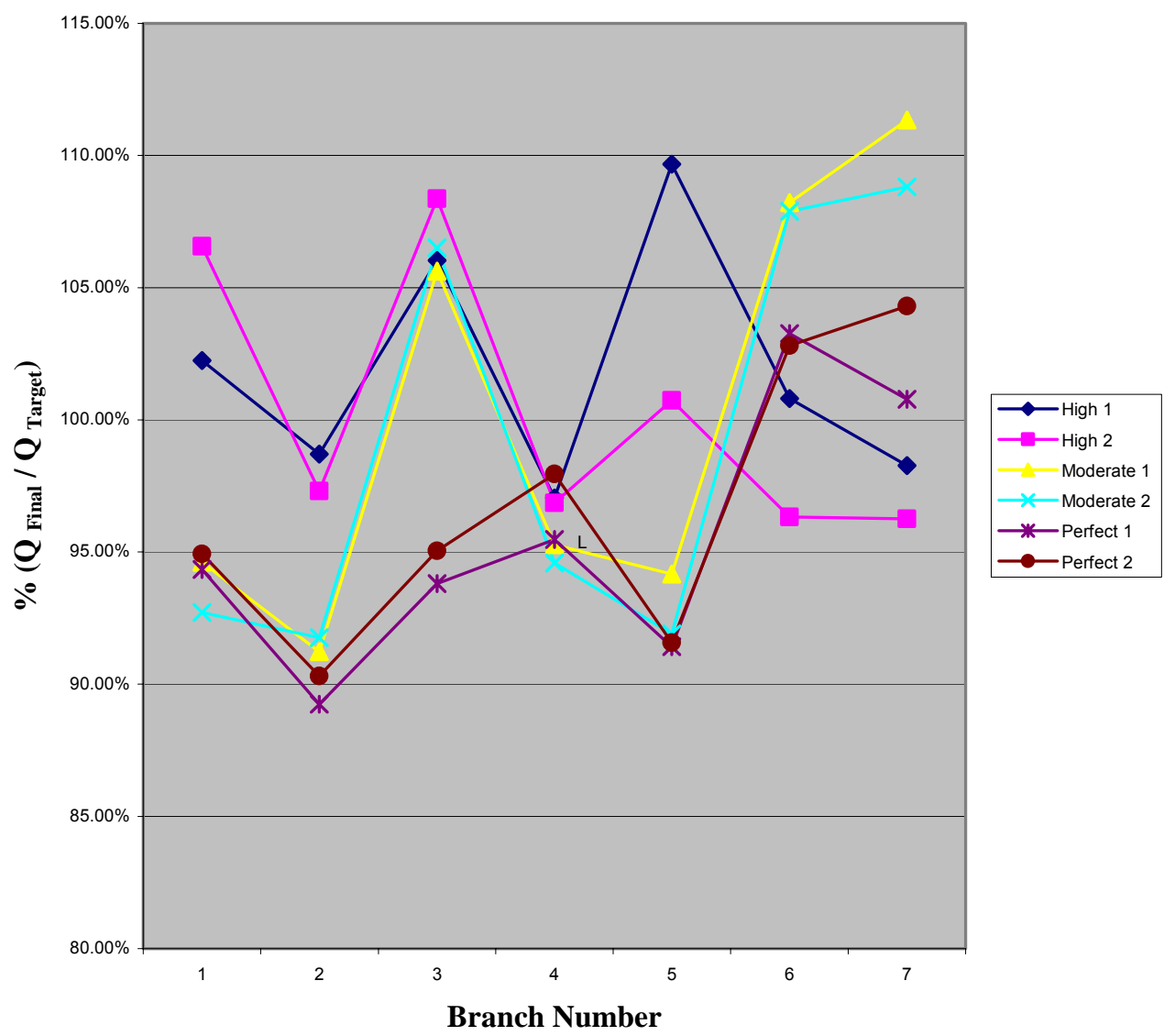

Figure 16. Branch Number vs. Percent ( $\left.Q_{\text {Final }} / \mathbf{Q}_{\text {Target }}\right)$

As can be seen in Figure 16, there is no obvious relationship between the $Q_{\text {ratio }}$ 
( $Q_{\text {Final }} / Q_{\text {Target }}$ ) for the branches and the level of the initial fan airflow. For a perfectly balanced system, a $\mathrm{Q}$ ratio with a value of 100 percent would be expected. This observation suggests that even substantially excessive (50 percent) initial fan speeds need not reduce the accuracy of balancing using this method. However, since the airflows in branches are mutually dependent, no statistical analysis could confirm or refute the lack of importance of initial airflow level to the accuracy of adjustments for each branch.

The results shown in Table 8 and Figure 16 are for two rounds of adjustments. Since Pitot traverses were not performed after the first round, it is not clear precisely how much the second round improved results over the first round. However, the investigator found that substantial re-adjustment of dampers was required for most branches between round one and round two.

Table 9. The Ratio of $Q_{\text {final }}$ / $Q_{\text {Target }}$ at the End of the First Round for the Low Airflow Condition.

\begin{tabular}{|l|c|c|c|c|c|c|c|c|}
\hline & \multicolumn{7}{|c|}{ Branch No. } & \\
\cline { 2 - 9 } & 1 & 2 & 3 & 4 & 5 & 6 & 7 & RMSE \\
\hline $\begin{array}{l}\text { Q Final/ Q } \\
\text { Target }\end{array}$ & $108.67 \%$ & $94.32 \%$ & $111.12 \%$ & $92.10 \%$ & $112.30 \%$ & $99.30 \%$ & $94.20 \%$ & $8.27 \%$ \\
\hline
\end{tabular}

A Pitot traverse was performed for one case (low), after the first round, with the RMSE value of 8.27 percent (Table 9), which is substantially higher than the 4.61 percent and 4.75 percent values observed after the second round. A third round of adjustments would be necessary to further improve the balance of airflow. This study did not investigate the effects of a third round of adjustments.

\subsection{Percent System Excess Airflow}

Although the errors for each branch are illuminating, owners of systems typically are concerned about minimizing the total airflow for the system. However, using the total airflow as a measure of success is misleading if one does not enforce the requirement that all hoods receive at least their $\mathrm{Q}_{\text {goal }}$ airflows. Since the fan level typically can be corrected by adjusting the fan speed, one could achieve zero excess airflow for the system with any distribution, no matter how different from the desired, just by adjusting the fan so that its 
airflow equals the desired sum of branch airflows.

Table 10. Percentage Excessive Airflow

\begin{tabular}{|c|c|c|c|c|c|c|}
\hline \multicolumn{7}{|c|}{ \% Excessive Airflow } \\
\hline $\begin{array}{l}\bar{\emptyset} \\
\bar{\varpi} \\
\frac{\tilde{\omega}}{0}\end{array}$ & 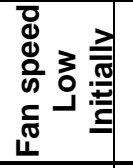 & 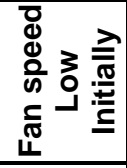 & 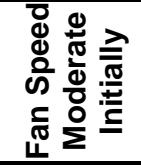 & 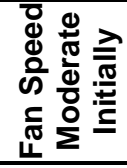 & 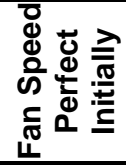 & 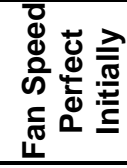 \\
\hline 1 & $5.36 \%$ & $10.72 \%$ & $3.71 \%$ & $1.11 \%$ & $6.06 \%$ & $5.12 \%$ \\
\hline 2 & $1.70 \%$ & $1.10 \%$ & $0 \%$ & $0 \%$ & $0 \%$ & $0 \%$ \\
\hline 3 & $9.26 \%$ & $12.59 \%$ & $15.79 \%$ & $15.09 \%$ & $5.46 \%$ & $5.25 \%$ \\
\hline 4 & $0 \%$ & $0.64 \%$ & $4.44 \%$ & $3.25 \%$ & $7.32 \%$ & $8.48 \%$ \\
\hline 5 & $13 \%$ & $4.66 \%$ & $3.21 \%$ & $0.17 \%$ & $2.65 \%$ & $1.40 \%$ \\
\hline 6 & $3.88 \%$ & $0.08 \%$ & $18.63 \%$ & $16.28 \%$ & $15.22 \%$ & $13.85 \%$ \\
\hline 7 & $1.26 \%$ & $0 \%$ & $22.05 \%$ & $17.07 \%$ & $12.83 \%$ & $15.49 \%$ \\
\hline System & $5.31 \%$ & $4.78 \%$ & $8.48 \%$ & $7.10 \%$ & $6.55 \%$ & $6.20 \%$ \\
\hline
\end{tabular}

As shown in Table 8, the final values of percent $Q_{\text {ratio }}\left(Q_{\text {Final }} / Q_{\text {Target }}\right)$ for some of the branches was as low as 90.37 percent. This meant that those branches would receive their required airflows only if the speed of the fan was increased. If the speed of the fan were increased so that the least $Q_{\text {ratio }}$ (i.e., minimum $Q_{\text {ratio }}$ ) equaled unity, then the air flow through the other branches all would increase in the same proportion (Guffey and Spann, 1999). Equation 17 was used to compute the amount of excess airflows that would exist for each branch after the fan speed was changed.

Percent excess $\mathrm{Q}_{\text {fan }}$ (percent excess of airflow through the fan) provides fair comparisons of adjust adequacy since it mathematically adjusts the fan airflow just enough that the most "starved" branch receives exactly its target airflow. As shown in Table 10, after two rounds of damper adjustments and after changing the fan speed, there was an average system excessive airflow (percent excess $Q_{\text {fan }}$ ) of 6.22 percent, with a range of 5.31 percent to 8.48 percent over all treatments and replications. The range of excessive airflows for branches was much broader, 0 to 22 percent. (The average for branches is best represented by the system value). Replications were consistent for the same target level of airflow, showing much less deviation than comparisons between results for different 
airflow goal levels.

An important question is whether the percent excess $\mathrm{Q}_{\text {fan }}$ varied due to the initial level of airflow. It is plausible that it would be more difficult to obtain excellent distributions when the initial airflow is high compared to the target levels because dampers must be inserted farther. That was not the case for these data. In fact, perfect fan level results were about the same as results for the low fan level, and the worst results occurred for the moderate case where the target airflow was a modest 10 percent less than the perfect level.

As explained earlier, the author had taken three levels of airflow (i.e., low, moderate, and perfect), because it was believed that as the fan was choked down, the dampers would be more difficult to adjust and deviations from the target airflows would increase.

A test was carried out to see if the levels of airflows were significant taking the percent of excessive airflow through the system as a dependant variable. The linear statistical model was formulated and can be written as

$$
\mathrm{y}_{\mathrm{ij}}=\mu+\tau_{\mathrm{i}}+\varepsilon_{\mathrm{ij}}
$$

where,

$\mathrm{i}=1,2,3$ (levels of airflow),

$\mathrm{j}=1,2$,

$\mu$ is the overall mean,

$\tau_{\mathrm{i}}$ is the effect of level I,

$\varepsilon_{\mathrm{ij}}$ is the random error component IID $\mathrm{N}\left(0, \sigma^{2}\right)$.

Table 11. The Percent of Excessive Airflow at Different Levels.

\begin{tabular}{|c|c|c|c|}
\hline & \multicolumn{3}{|c|}{ LEVELS } \\
\hline \multirow{3}{*}{ 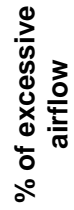 } & Perfect & Moderate & Low \\
\hline & $6.2 \%$ & $7.1 \%$ & $4.8 \%$ \\
\hline & $6.56 \%$ & $8.5 \%$ & $5.3 \%$ \\
\hline
\end{tabular}


The percent of excessive airflow for each level of airflow is shown in Table 11. An ANOVA was performed to test the significance of the levels of airflow.

Table 12. ANOVA to Test the Significance of Levels of Airflow

\begin{tabular}{|c|c|c|c|c|c|}
\hline Source & Df & Sums of Squares & $\begin{array}{c}\text { Mean } \\
\text { Square }\end{array}$ & F-ratio & Prob > F \\
\hline Levels of Airflow & 2 & 7.57 & 3.79 & 9.78 & 0.049 \\
\hline Error & 3 & 1.17 & 0.38 & & \\
\hline Total & 5 & 8.74 & & & \\
\hline
\end{tabular}

As shown in Table 12, the level of airflow was marginally significant $(\mathrm{p}=0.049)$. This means that the different levels of airflow may have a slight influence on the deviation of final airflows from the targets and that choking down the fan does not result in a larger deviation from the target airflows.

\subsection{Comparison of the Common Method to the $S P_{h}$ Goal Ratio Method.}

In this section the results for this study are compared to results found by Dodrill (2004), who used the $\mathrm{SP}_{\mathrm{h}}$ goal ratio method proposed by Guffey (2004). This study and Dodrill's study were performed on the same ventilation system and used the same target distribution.

As shown in Table 13, Dodrill found much lower percent excess $Q_{\text {fan }}$ values than were found here using the common method. Indeed, the best result using the common method (5.3 percent) was twice as high as the worst result ( 2.13 percent) found by Dodrill. Note that the initial level of fan airflow is irrelevant for the $\mathrm{SP}_{\mathrm{h}}$ goal ratio method since it normalizes for airflows. Therefore, all levels of airflow are perfect for the $\mathrm{SP}_{\mathrm{h}}$ goal ratio method. 
Table 13. Comparison of Results for the Two Methods

\begin{tabular}{|c|c|c|c|c|c|c|c|c|c|c|}
\hline Method & $\begin{array}{c}\text { Initial } \\
\text { Fan } \\
\text { Level } \\
\end{array}$ & Distribution & $\begin{array}{l}Q_{\text {system }} \\
\text { Target } \\
\text { in cfm }\end{array}$ & $\begin{array}{c}Q_{\text {system }} \\
\text { after } \\
\text { damper } \\
\text { adjustment } \\
\text { and before } \\
\text { fan } \\
\text { adjustment } \\
\text { in cfm }\end{array}$ & $\begin{array}{c}\mathbf{Q}_{\text {system }} \\
\text { after fan } \\
\text { adjustment } \\
\text { in cfm }\end{array}$ & $\begin{array}{c}\text { Max \% } \\
\text { Qbr after }_{\text {fan }} \\
\text { adjustment }\end{array}$ & $\begin{array}{c}\text { Excess } \\
\% \\
Q_{\text {system }}\end{array}$ & $\begin{array}{c}\text { SP }_{\text {fan }} \\
\text { observed } \\
\text { before fan } \\
\text { adjustment } \\
\text { in inches } \\
\text { water } \\
\text { gauge }\end{array}$ & $\begin{array}{c}\text { Total } \\
\text { Pressure } \\
\text { after fan } \\
\text { adjustment } \\
\text { in inches } \\
\text { water } \\
\text { gauge }\end{array}$ & $\begin{array}{c}\text { RMSE } \\
\text { for } \\
\text { excessive } \\
\text { airflow }\end{array}$ \\
\hline Common & low & A & 1431 & 1463.0 & 1507.1 & 1.14 & $5.30 \%$ & 5.63 & 7.10 & 0.046 \\
\hline Common & Low & A & 1431 & 1443.3 & 1499.6 & 1.13 & $6.20 \%$ & 5.63 & 7.11 & 0.048 \\
\hline Common & Moderate & A & 1951 & 1931.4 & 2117.0 & 1.22 & $8.50 \%$ & 4.03 & 5.08 & 0.075 \\
\hline Common & Moderate & A & 1951 & 1916.2 & 2088.2 & 1.19 & $7.10 \%$ & 4.04 & 5.10 & 0.075 \\
\hline Common & Perfect & A & 2147 & 2034.7 & 2280.0 & 1.16 & $6.56 \%$ & 3.09 & 3.90 & 0.065 \\
\hline Common & Perfect & A & 2147 & 2058.6 & 2279.6 & 1.16 & $6.20 \%$ & 3.09 & 3.90 & 0.059 \\
\hline Guffey & Perfect & A & 2360 & 2143.1 & 2408.0 & 1.04 & $2.05 \%$ & 3.06 & 3.86 & 0.012 \\
\hline Guffey & Perfect & A & 2360 & 2150.0 & 2410.3 & 1.03 & $2.13 \%$ & 3.03 & 3.83 & 0.011 \\
\hline Guffey & Perfect & B & 2550 & 2247.4 & 2556.8 & 1.02 & $0.28 \%$ & 2.66 & 3.36 & 0.006 \\
\hline Guffey & Perfect & B & 2550 & 2271.1 & 2595.5 & 1.05 & $1.35 \%$ & 2.67 & 3.37 & 0.013 \\
\hline
\end{tabular}

Dodrill used only one and one-half rounds of adjustment instead of the two employed here but produced much lower percent excess Airflow values. The range for Dodrill was 2.05 to 2.13 percent for the perfect fan airflow condition, while the range for the same conditions for this study was 6.2 to 6.56 percent. For the low fan airflow conditions the range here was 5.3 to 6.2 percent. It is interesting to note that when a different distribution of airflow was used in this system, Dodrill found the percent of excess air flow through the system to be even lower (see the last two rows in Table.13).

The magnitudes for the deviations for individual branches showed similar differences for the two methods. As shown in Table 12, the percentage of excessive airflow for any branch in the system using the common method ranged from 1.82 to 22.6 percent while the corresponding value for the Dodrill study was 1.82 to 4.56 percent. The results are plotted in Figure 17. Likewise; the root mean squared deviation for the excessive airflows in the system (RMS) for Dodrill never exceeded 2.7 percent while the RMS for the 
common method ranged from 4.6 to 7.5 percent.

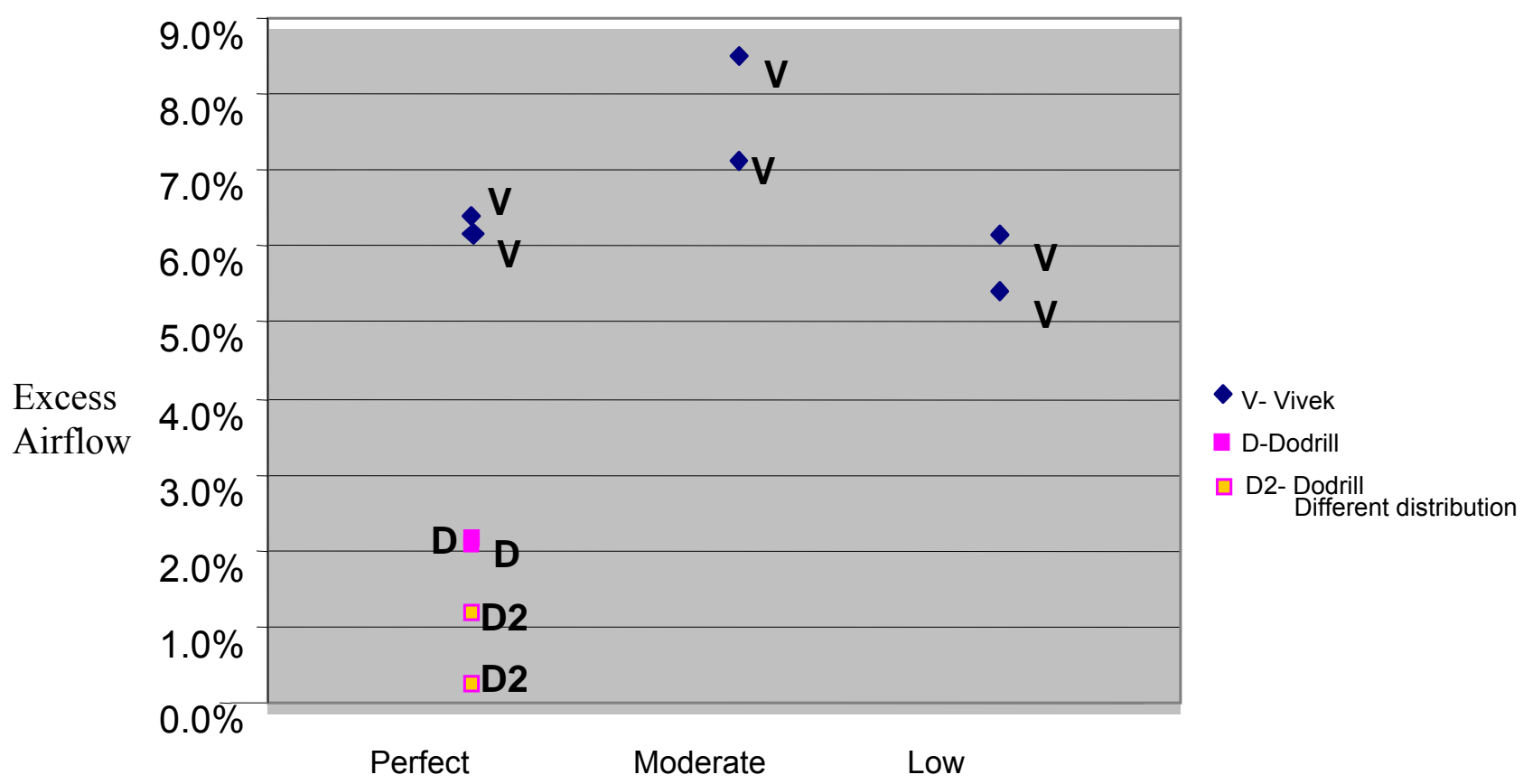

Figure 17. Percentage of Excessive Airflow for both Methods

A test was conducted to determine the significance of the two methods (i.e. common method and $\mathrm{SP}_{\mathrm{h}}$ Goal ratio method). Since levels of target airflows were shown to be marginally significant, the perfect airflow condition was used. A t-test was carried out to test the significance of the methods for the perfect airflow condition.

The hypothesis to be tested was:

$\mathrm{H}_{\mathrm{o}}: \mu_{1}=\mu_{2}$

$\mathrm{H}_{\mathrm{a}}: \mu_{1}>\mu_{2}$

Where: $\mu_{1}=$ population mean for percent excessive airflow for the system that was obtained by using the common method for the perfect airflow levels.

$\mu_{2}=$ mean percent excessive airflow for the system that was obtained by using $\mathrm{SP}_{\mathrm{h}}$ Goal ratio method.

$S_{1}^{2}=0.064$ and $S_{2}^{2}=0.032$. It can be assumed that $\sigma_{1}^{2} \neq \sigma_{2}^{2}$ 
If $t_{O}>t_{\alpha, v}, \mathrm{H}_{\mathrm{o}}$ can be rejected.

$$
t_{O}=\frac{\bar{y}_{1}-\bar{y}_{2}}{\sqrt{\frac{S_{1}^{2}}{n_{1}}+\frac{S_{2}^{2}}{n_{2}}}}
$$

and

$$
\begin{gathered}
v=\frac{\left(\frac{S_{1}^{2}}{n_{1}}+\frac{S_{2}^{2}}{n_{2}}\right)^{2}}{\sqrt{\frac{S_{1}^{2} / n_{1}}{n_{1}-1}+\frac{S_{2}^{2} / n_{2}}{n_{2}-1}}} \\
t_{O}=\frac{6.38-2.09}{\sqrt{\frac{0.064}{2}+\frac{0.0032}{2}}}=23.26 \quad v=\frac{\left(\frac{0.064}{2}+\frac{0.0032}{2}\right)^{2}}{\sqrt{\frac{0.032}{2-1}+\frac{0.0016}{2-1}}} \approx 1
\end{gathered}
$$

$\mathrm{n}_{1}$ and $\mathrm{n}_{2}$ are the sample sizes for the common method and the $\mathrm{SP}_{\mathrm{h}}$ ratio method, respectively.

$$
t_{0.05,1}=6.31
$$

Since $t_{O}>t_{\alpha, v}, \mathrm{H}_{\mathrm{o}}$ can be rejected, and it can concluded that the two methods differ significantly.

\subsubsection{Static Pressure of the System}

As the target air flows decreased, the dampers were pushed in further. This resulted in an increase in the speed of the fan, which in turn resulted in the increase of the static hood pressure of the fan. The static pressure for the fan increased from 3.08 inches water gauge to 5.62 inches water gauge as the dampers increasingly choked the fan. 


\subsubsection{Time Taken to Perform the Adjustments}

Finally, the time recorded by the author to perform these two rounds of tests was around 180 minutes. Dodrill (2004) claimed his adjustments took 150 minutes on the same ventilation system. However, since the time depended on the patience and accuracy of the investigator, it is not clear whether this difference was due to the methods or the investigators.

\subsection{Conclusions}

From the results of this study, an average pipe factor of 0.9 over all branches was shown to be acceptable. However, the pipe factor varied significantly $(\mathrm{p}<0.05)$ with diameter and branch number and airflow levels.

From the results of this study, it can be concluded that for this experiment the common method typically followed by practitioners produced excessive system airflows of 5.21 to 8.48 percent. The effects of deviations between target and initial levels were not clear.

It was observed that for the pipe factor study, accuracy was affected by an apparent error in conducting Pitot traverses. For the damper adjustment study, results were found on a single system for a single distribution of airflow. The measurement conditions were much better than what a typical practitioner would experience. It is possible that the range of errors would be greater in the field for a similar change in distributions for a similar system. In addition, use of $\mathrm{VP}_{\mathrm{cl}}$ values would have contributed to the errors in adjustment, but the amount could not be determined in this experiment. It is possible that the range of errors would be reduced somewhat if full Pitot traverses had been used instead.

\subsection{Recommendations for Future Work}

The results of this study solely apply to the duct configuration and distribution system studied. The efficacy of damper adjustments could be very different for other systems or with different distributions. It would be useful to have similar studies done on other systems, especially working systems in the field, for various distributions.

There are many unanswered questions concerning balancing with dampers. Future 
research should include:

1. Determining the relationship between resistance to flow and insertion depth of dampers.

2. The effect of the order of damper adjustment. It is possible that other orders of adjustment would produce different results.

3. It must be ensured that the Pitot probe be inserted through the center of the slot (see Figure 14) instead of the downstream edge of the slot. If the Pitot tube is inserted in the downstream edge of the slot, the curve of the Pitot probe where it goes from horizontal to vertical would come up against the inside of the duct, preventing the Pitot tube from being moved completely to the first and second positions. Since the probe is somewhat flexible, it could simply bend the probe out of line with the duct, changing the actual insertion depth slightly. Hence the measurements taken would be inaccurate.

4. A study could be conducted to determine the amount of energy that could be saved by employing the $\mathrm{SP}_{\mathrm{h}}$ Goal ratio method while balancing an exhaust ventilation system. 


\section{Bibliography}

1. ASHRAE, (2005). A Handbook on Heating, Ventilating, and Air-Conditioning Applications. American Society of Heating, Refrigerating and Air-Conditioning Engineers. Inc.

2. ACGIH, (2005). A Manual of Recommended Practice in Industrial Ventilation. American Conference of Governmental Industrial Hygienists.

3. Besant, R. W. and Asiedu, Y. (2000). "Sizing and Balancing Air Duct Systems." American Society of Heating, Refrigeration and Air Conditioning Engineers Journal (December 2000): pp 24-36

4. Chung, T.J. (2002). Computational fluid dynamics. Cambridge University Press Publication.

5. Dodrill, M. (2004). "Experimental Validation of the Target Hood Static Pressure Balancing Method for Exhaust Ventilation Systems."

6. Montgomery, D. (2001). Design and Analysis of Experiments. Published by John Wiley \& Sons Inc.

7. Geiger, H. (1997). "Evaluation of a Proposed Static Pressure Ratio Balancing Method for Exhaust Ventilation Systems". Masters Thesis, University of Washington, Seattle.

8. Guffey, S.E. (2005), "Balancing Duct Systems with Dampers." (Unpublished article 2005).

9. Guffey, S. E. and Booth, D. W. (1999). "Comparison of Pitot Traverses Taken at Varying Distances Downstream of Obstructions." American Industrial Hygiene Association Journal. Vol. 60, No. 2. (1999): pp. 165-174.

10. Guffey S.E. and Booth D.W.(2001). "An Evaluation of Industrial Ventilation Troubleshooting Methods in Experimental Systems." Industrial Hygiene Association Journal, Vol. 62, No. 6, pp. 671-679.

11. Guffey, S.E.; Slagley, J. and El-Sotouhy, Ahmed; "Proposed Additions to Ventilation Duct Design Procedures.” (unpublished manuscript. July 2004.)

12. Guffey, S. E. and Hickey, J. L. S. (1983). "Equations for Redesign of Existing Ventilation Systems." American Industrial Hygiene Association Journal 44(11):819827. (1983): pp 819-127.

13. Guffey, S. E. (1993). "Air-Flow Redistribution in Exhaust Ventilation Systems Using Dampers and Static Pressure Ratios." Applied Occupational Environmental Hygiene 8(3) (March 1993): pp 168-177. 
14. Guffey, S. E. (1990). "Simplifying Pitot Traverses." Applied Occupational Environmental Hygiene 5(2). (February 1990): pp 95-100.

15. Guffey, S. E and Spann J.G. (1999). "Experimental Investigation of Power Loss coefficients and Static Pressure Ratios in Industrial Exhaust Ventilation Systems." Industrial Hygiene Association.

16.Haines, R. (1988). Heating, Ventilation and Air Conditioning Systems Design Handbook. Published by TAB Books Incorporated.

17. Jorgensen, R. (editor) (1983). Fan Engineering. Eighth Edition. Published by Buffalo Forge Company.

18. McLoone, H.E.; Guffey, S.E. and Curran, J.C. (1993). "Effects of Shape, Size, and Air Velocity on Entry Loss Factors of Suction Hoods." American Industrial Hygiene Association Journal, 54(3):87-94 (1993).

19. SMACNA, (1993) Testing and Balancing Procedural Guide. Sheet Metal and Air Conditioning Contractors' National Association Inc. 


\section{Appendix}

\section{Appendix 1.}

\section{Sheet Metal and Air Conditioning Contractors' National Association (SMACNA) methods}

\section{SMACNA's stepwise method (paraphrased)}

Starting at the main supply duct closest to the fan, or with the highest percentage of required airflow, conduct Pitot tube traverses on all main supply and major branch ducts to determine the airflow distribution. Adjust the volume damper on each branch that has a high airflow. Monitor the static pressure at a point downstream of the balancing damper. Slowly close the damper until the SP comes down to a new required SP determined by the equation

$$
\frac{\mathrm{SP}_{2}}{\mathrm{SP}_{1}}=\left(\frac{\text { airflow }_{2}}{\text { airflow }_{1}}\right)^{2}
$$

This should approximately give the correct airflow for the zone. The procedure should be used on each zone with high airflow, usually starting with the highest one first. Then remeasure the SP in all zones. There usually will be some interactions between zones. Some of the adjusted zones may need adjusting again. The zones that were low in airflow should have increased, and now some of these may be high, and they may need adjusting. After the zones are adjusted to the new calculated SP, proceed to the terminal units. There will be instances when a branch damper will need adjusting but there won't be any satisfactory location for a Pitot tube traverse. In this instance, it will be necessary to take airflow readings at all of the terminals in the zone and total them. Use this total, take a reference SP as detailed earlier, and then proceed to the balance zone. Measure and record the airflow at each terminal in the system. In making adjustments, adjust volume dampers instead of face dampers. Review the readings and start adjusting the terminals that are highest on airflow. On the first adjusting pass through the system, it usually helps to throttle these terminals to about 
10 percent under design airflow. This will allow for possible airflow build up as other terminals are adjusted. After adjusting the high airflow volume terminals, proceed to make another pass through the entire zone or system. Adjust each terminal to the specified airflow, assuming that sufficient air is available. After two adjusting passes, most systems should be in a good balance. An additional pass may be necessary to fine tune the system. Mark all dampers at the point of final adjustment for ease of resetting in the event of tampering. Verify the fan capacity and operating conditions again and make final adjustments to the fan drive if necessary. After testing and recording all of the terminal units, total the readings on a zone or branch basis. Compare the totals to the comparable zone duct traverse reading and required airflow. The total airflow for the terminal units should be close to the traverse reading for the zone or branch. The terminal unit total usually will be a little lower due to allowable duct leakage. If the measured airflow of the supply air fan, central return air fan, or central exhaust air fan varies more than the specified design plus allowable leakage, adjust the drive of each fan to obtain the approximate required airflow. If the adjustments were severe enough to cause a considerable change in total airflow, all the above steps must be repeated until proper supply, return, outside, exhaust, and spill air quantities are achieved.

2. SMACNA's proportional balancing method (paraphrased)

Select the supply air duct branch farthest from the fan. All terminal units or outlets should be numbered on a schematic drawing. Record the measured airflows $\mathrm{Q}_{\mathrm{m}}$ from each of the terminal outlets on the selected branch duct. Calculate the percentage $(X \%)$ of design airflow $\left(Q_{d}\right)$ for each outlet $\left(Q_{m} / Q_{d}=X \%\right)$. The outlets are renumbered in their degree of percentage of design from the lowest to the highest. The branch damper for the lowest percentage of airflow is not adjusted. The damper for the next lowest percentage of design is adjusted until the airflow volume decreases to the average of the above two branches. This should be verified by measurement, and the two outlets should be in balance. The branch that is the next lowest in percentage of design is adjusted till it comes to the average of the previous and the current branch. The above three branches should now be in balance. The 
procedure is followed, proportionally balancing the next highest percentage of design outlet to the previous one balanced. This should even out all the outlets balanced earlier. If a branch duct has outlets with varying airflows, the percentage of design is calculated for each and the same procedures are used, balancing to the percentage of design airflow for each. Upon completion of proportional balancing of all outlets and branches, recheck the supply air fan capacity to the final $\mathrm{Q}_{\mathrm{m}} / \mathrm{Q}_{\mathrm{d}}$ percentage. If measured airflow $\mathrm{Q}_{\mathrm{m}}$ is lower than designed airflow $\mathrm{Q}_{\mathrm{d}}$, the fan airflow volume must be increased to the design airflow and all outlets should be increased proportionally to their design airflow $\left(\mathrm{Q}_{\mathrm{d}}\right)$.

\section{Appendix 2}

Table 1.Velocities at Each Insertion Depth after Conducting a Pitot Traverse

\begin{tabular}{|c|c|c|c|c|c|c|c|c|c|c|c|}
\hline \multicolumn{12}{|c|}{ Velocities in meters/second } \\
\hline Branch No & $\underline{\mathrm{V} 1}$ & $\underline{\mathrm{V} 2}$ & $\underline{\mathrm{V} 3}$ & $\underline{\mathrm{V} 4}$ & $\underline{\text { V5 }}$ & $\underline{\mathrm{CL}}$ & $\underline{\mathrm{V} 6}$ & $\underline{\mathrm{V} 7}$ & $\underline{\mathrm{V} 8}$ & $\underline{\mathrm{V} 9}$ & $\underline{\mathrm{V} 10}$ \\
\hline 1 & 17.29 & 17.86 & 18.10 & 18.65 & 18.96 & 18.84 & 18.69 & 18.32 & 17.77 & 14.09 & 13.44 \\
\hline 2 & 17.77 & 18.96 & 19.07 & 18.86 & 18.55 & 18.40 & 18.36 & 17.47 & 16.96 & 13.24 & 13.03 \\
\hline 3 & 16.92 & 17.59 & 18.23 & 18.38 & 19.51 & 19.01 & 18.70 & 19.46 & 18.40 & 15.03 & 14.66 \\
\hline 4 & 16.99 & 17.56 & 18.68 & 19.53 & 20.12 & 21.08 & 21.40 & 20.15 & 19.84 & 17.20 & 14.75 \\
\hline 5 & 20.43 & 21.33 & 22.20 & 22.31 & 20.49 & 22.45 & 22.65 & 21.68 & 21.07 & 16.00 & 15.11 \\
\hline 6 & 14.63 & 14.93 & 16.52 & 16.59 & 16.39 & 17.02 & 17.11 & 17.07 & 15.00 & 12.57 & 11.66 \\
\hline \multirow[t]{2}{*}{7} & 14.19 & 15.20 & 16.13 & 16.09 & 15.34 & 15.42 & 15.47 & 14.97 & 14.40 & 12.57 & 10.93 \\
\hline & V11 & $\underline{\mathrm{V} 12}$ & $\underline{\mathrm{V} 13}$ & $\underline{\mathrm{V} 14}$ & $\underline{\mathrm{V} 15}$ & $\underline{\mathrm{CL}}$ & $\underline{\mathrm{V} 16}$ & V17 & $\underline{\mathrm{V} 18}$ & $\underline{\mathrm{V} 19}$ & $\underline{\mathrm{V} 20}$ \\
\hline 1 & 16.97 & 18.64 & 19.11 & 18.54 & 18.73 & 19.00 & 18.84 & 18.98 & 18.30 & 13.27 & 14.03 \\
\hline 2 & 15.51 & 15.43 & 16.92 & 16.59 & 17.63 & 18.75 & 19.27 & 18.46 & 17.64 & 13.22 & 13.35 \\
\hline 3 & 17.62 & 18.17 & 18.33 & 18.54 & 19.46 & 19.24 & 19.42 & 18.73 & 18.24 & 16.14 & 14.50 \\
\hline 4 & 18.04 & 18.92 & 20.29 & 20.81 & 20.37 & 20.56 & 19.74 & 18.36 & 16.99 & 14.50 & 14.35 \\
\hline 5 & 22.83 & 22.09 & 23.02 & 20.73 & 22.64 & 22.67 & 22.12 & 20.40 & 20.31 & 15.07 & 14.47 \\
\hline 6 & 14.66 & 15.80 & 16.41 & 15.61 & 17.01 & 17.23 & 17.29 & 17.07 & 16.81 & 13.85 & 12.07 \\
\hline 7 & 13.00 & 13.22 & 13.85 & 14.18 & 15.02 & 15.93 & 15.80 & 15.36 & 14.54 & 11.59 & 11.40 \\
\hline
\end{tabular}




\section{Appendix 3}

Table 1. Target Airflows and Velocity Pressures for Low Airflow (first repetition)

\begin{tabular}{|c|c|c|c|c|c|c|c|c|c|c|}
\hline & & & Low & $\begin{array}{c}\text { The } \mathrm{VP}_{\mathrm{cl}} \text { at } \\
\text { the }\end{array}$ & \multirow{2}{*}{$\begin{array}{l}\mathrm{VP} \text { at the end of } \\
\text { 2nd } \\
\text { round/Target VP }\end{array}$} & \multirow{2}{*}{$\mathrm{Q}_{\text {target }}$} & \multirow[b]{2}{*}{$\mathrm{Q}_{\text {final }}$} & \multirow[b]{2}{*}{$Q_{\text {goal }}$} & \multirow[b]{2}{*}{$Q_{\text {final }}$} & \multirow[b]{2}{*}{$\begin{array}{l}\mathrm{Q}_{\text {final }} / \\
\mathrm{Q}_{\text {Target }}\end{array}$} \\
\hline BrNo & Dia & Order & $\begin{array}{l}\mathrm{VP}_{\mathrm{cl}} \\
\text { Target }\end{array}$ & \begin{tabular}{|c} 
end of round \\
2
\end{tabular} & & & & & & \\
\hline 1 & 4.85 & 1 & 0.213 & 0.225 & 1.05 & 215.83 & 323.75 & 350 & 220.69 & 1.02 \\
\hline 2 & 3.84 & 6 & 0.541 & 0.529 & 0.98 & 215.43 & 323.15 & 360 & 212.63 & 0.99 \\
\hline 3 & 4.85 & 2 & 0.270 & 0.287 & 1.06 & 242.80 & 364.2 & 400 & 257.45 & 1.06 \\
\hline 4 & 3.84 & 7 & 0.666 & 0.643 & 0.96 & 239.13 & 358.7 & 400 & 232.07 & 0.97 \\
\hline 5 & 3.84 & 5 & 0.626 & 0.685 & 1.09 & 231.76 & 347.65 & 380 & 254.16 & 1.10 \\
\hline 6 & 4.85 & 3 & 0.142 & 0.144 & 1.02 & 175.93 & 263.9 & 290 & 177.35 & 1.01 \\
\hline 7 & 3.84 & 4 & 0.141 & 0.138 & 0.98 & 110.13 & 165.2 & 180 & 108.22 & 0.98 \\
\hline & & & & & Total & 1431 & 2146 & 2360 & 1463 & \\
\hline & & & & & & & & & & \\
\hline
\end{tabular}

Table 2. Target Airflows and Velocity Pressures for Low Airflow (second repetition)

\begin{tabular}{|c|c|c|c|c|c|c|c|c|c|c|}
\hline \multirow[b]{2}{*}{ BrNo } & \multirow[b]{2}{*}{ Dia } & \multirow[b]{2}{*}{ Order } & \multirow{2}{*}{\begin{tabular}{|c|} 
Low \\
$\mathrm{VP}_{\mathrm{cl}}$ Target \\
\end{tabular}} & \multirow{2}{*}{$\begin{array}{l}\text { The } \mathrm{VP}_{\mathrm{cl}} \text { at the } \\
\text { end of round } 2\end{array}$} & \multirow{2}{*}{$\begin{array}{c}\mathrm{VP} \text { at the end of } \\
\text { 2nd round/Target } \\
\text { VP }\end{array}$} & \multirow[b]{2}{*}{$\mathrm{Q}_{\text {target }}$} & \multirow[b]{2}{*}{$\mathrm{Q}_{\text {final }}$} & \multirow[b]{2}{*}{$Q_{\text {goal }}$} & \multirow[b]{2}{*}{$Q_{\text {final }}$} & \multirow[b]{2}{*}{$\begin{array}{l}\mathrm{Q}_{\text {Final }} / \\
\mathrm{Q}_{\text {Target }}\end{array}$} \\
\hline & & & & & & & & & & \\
\hline 1 & 4.85 & 1 & 0.21 & 0.23 & 1.06 & 215.83 & 323.75 & 350 & 230 & 1.07 \\
\hline 2 & 3.84 & 6 & 0.54 & 0.53 & 0.99 & 215.43 & 323.15 & 360 & 209.62 & 0.97 \\
\hline 3 & 4.85 & 2 & 0.27 & 0.29 & 1.06 & 242.80 & 364.20 & 400 & 263.10 & 1.08 \\
\hline 4 & 3.84 & 7 & 0.67 & 0.65 & 0.98 & 239.13 & 358.70 & 400 & 231.63 & 0.97 \\
\hline 5 & 3.84 & 5 & 0.63 & 0.63 & 1.01 & 231.77 & 347.65 & 380 & 233.45 & 1.01 \\
\hline 6 & 4.85 & 3 & 0.14 & 0.14 & 0.96 & 175.93 & 263.90 & 290 & 169.47 & 0.96 \\
\hline \multirow[t]{2}{*}{7} & 3.84 & 4 & 0.14 & 0.14 & 0.98 & 110.13 & 165.20 & 180 & 106 & 0.96 \\
\hline & & & & & Total & 1431 & 2146 & 2360 & 1443 & \\
\hline & & & & & & & & & & \\
\hline
\end{tabular}


Table 3. Target Airflows and Velocity Pressures for Perfect Airflow (first repetition)

\begin{tabular}{|c|c|c|c|c|c|c|c|c|c|c|}
\hline \multirow[b]{2}{*}{$\mathrm{BrNo}$} & \multirow[b]{2}{*}{ Dia } & \multirow[b]{2}{*}{ Order } & \multirow{2}{*}{$\begin{array}{l}\text { Perfect Ratio } \\
\mathrm{VP}_{\mathrm{cl}} \text { Target } \\
\end{array}$} & \multirow{2}{*}{$\begin{array}{l}\text { The VPcl } \\
\text { at the } \\
\text { end of } \\
\text { round } 2 \\
\end{array}$} & \multirow{2}{*}{$\begin{array}{l}\mathrm{VP} \text { at the end } \\
\text { of } 2 \text { nd } \\
\text { round/Target } \\
\text { VP }\end{array}$} & \multirow[b]{2}{*}{$\mathrm{Q}_{\text {target }}$} & \multirow[b]{2}{*}{$Q_{\text {final }}$} & \multirow[b]{2}{*}{$Q_{\text {goal }}$} & \multirow[b]{2}{*}{$Q_{\text {Final }}$} & \multirow[b]{2}{*}{$\begin{array}{c}\mathrm{Q}_{\text {Final }} / \mathrm{Q} \\
\text { Target } \\
\end{array}$} \\
\hline & & & & & & & & & & \\
\hline 1 & 4.85 & 1 & 0.48 & 0.45 & 0.95 & 323.75 & 323.75 & 350 & 305.43 & 0.94 \\
\hline 2 & 3.84 & 6 & 1.22 & 1.10 & 0.90 & 323.15 & 323.15 & 360 & 288.38 & 0.89 \\
\hline 3 & 4.85 & 2 & 0.61 & 0.57 & 0.94 & 364.20 & 364.20 & 400 & 341.65 & 0.94 \\
\hline 4 & 3.84 & 7 & 1.50 & 1.41 & 0.94 & 358.70 & 358.70 & 400 & 342.47 & 0.95 \\
\hline 5 & 3.84 & 5 & 1.41 & 1.30 & 0.92 & 347.65 & 347.65 & 380 & 317.77 & 0.91 \\
\hline 6 & 4.85 & 3 & 0.32 & 0.33 & 1.04 & 263.90 & 263.90 & 290 & 272.51 & 1.03 \\
\hline \multirow[t]{2}{*}{7} & 3.84 & 4 & 0.32 & 0.33 & 1.03 & 165.20 & 165.20 & 180 & 166.48 & 1.01 \\
\hline & & & & & Total & 2146 & 2146 & 2360 & 2034 & \\
\hline
\end{tabular}

Table 4. Target Airflows and Velocity Pressures for Perfect Airflow (second repetition)

\begin{tabular}{|c|c|c|c|c|c|c|c|c|c|c|}
\hline \multirow[b]{2}{*}{ BrNo } & \multirow[b]{2}{*}{ Dia } & \multirow[b]{2}{*}{ Order } & \multirow{2}{*}{$\begin{array}{c}\text { Perfect } \\
\text { Ratio } \\
\mathrm{VP}_{\mathrm{cl}} \text { Target }\end{array}$} & \multirow{2}{*}{$\begin{array}{l}\text { The } \mathrm{VP}_{\mathrm{cl}} \text { at the } \\
\text { end of round } 2\end{array}$} & \multirow{2}{*}{$\begin{array}{c}\text { VP at the end of } \\
\text { 2nd round/Target } \\
\text { VP }\end{array}$} & \multirow[b]{2}{*}{$\mathrm{Q}_{\text {target }}$} & \multirow[b]{2}{*}{$\mathrm{Q}_{\text {final }}$} & \multirow[b]{2}{*}{$Q_{\text {goal }}$} & \multirow[b]{2}{*}{$\mathrm{Q}_{\text {Final }}$} & \multirow[b]{2}{*}{$\begin{array}{c}\mathrm{Q}_{\text {Original }} / \\
\mathrm{Q}_{\text {Target }}\end{array}$} \\
\hline & & & & & & & & & & \\
\hline 1 & 4.85 & 1 & 0.48 & 0.46 & 0.96 & 323.75 & 323.75 & 350 & 307.33 & 0.95 \\
\hline 2 & 3.84 & 6 & 1.22 & 1.12 & 0.92 & 323.15 & 323.15 & 360 & 291.82 & 0.90 \\
\hline 3 & 4.85 & 2 & 0.61 & 0.59 & 0.96 & 364.20 & 364.20 & 400 & 346.16 & 0.95 \\
\hline 4 & 3.84 & 7 & 1.50 & 1.45 & 0.97 & 358.70 & 358.70 & 400 & 351.38 & 0.98 \\
\hline 5 & 3.84 & 5 & 1.41 & 1.32 & 0.94 & 347.65 & 347.65 & 380 & 318.33 & 0.92 \\
\hline 6 & 4.85 & 3 & 0.32 & 0.33 & 1.03 & 263.90 & 263.90 & 290 & 271.32 & 1.03 \\
\hline \multirow[t]{2}{*}{7} & 3.84 & 4 & 0.32 & 0.33 & 1.04 & 165.20 & 165.20 & 180 & 172.30 & 1.04 \\
\hline & & & & & Total & 2146 & 2146 & 2360 & 2058 & \\
\hline
\end{tabular}


Table 5. Target Airflows and Velocity Pressures for Moderate Airflow (first repetition)

\begin{tabular}{|c|c|c|c|c|c|c|c|c|c|c|}
\hline \multirow[b]{2}{*}{$\mathrm{BrNo}$} & \multirow[b]{2}{*}{ Dia } & \multirow[b]{2}{*}{ Order } & \multirow{2}{*}{$\begin{array}{l}\text { Moderate } \\
\mathrm{VP}_{\mathrm{cl}} \text { Target }\end{array}$} & \multirow{2}{*}{$\begin{array}{l}\text { The } \mathrm{VP}_{\mathrm{cl}} \text { at } \\
\text { the } \\
\text { end of round } \\
2\end{array}$} & \multirow{2}{*}{$\begin{array}{l}\text { VP at the end } \\
\text { of } 2 \text { nd } \\
\text { round/Target } \\
\text { VP }\end{array}$} & & \multirow[b]{2}{*}{$\mathrm{Q}_{\text {final }}$} & \multirow[b]{2}{*}{$Q_{\text {goal }}$} & \multirow[b]{2}{*}{$Q_{\text {final }}$} & \multirow[b]{2}{*}{$Q_{\text {final }} / Q_{\text {target }}$} \\
\hline & & & & & & $\mathrm{Q}_{\text {target }}$ & & & & \\
\hline 1 & 4.85 & 1 & 0.40 & 0.38 & 0.96 & 294.32 & 323.75 & 350 & 278.48 & 0.95 \\
\hline 2 & 3.84 & 6 & 1.01 & 0.90 & 0.90 & 293.77 & 323.15 & 360 & 268.01 & 0.91 \\
\hline 3 & 4.85 & 2 & 0.50 & 0.54 & 1.08 & 331.09 & 364.20 & 400 & 349.74 & 1.06 \\
\hline 4 & 3.84 & 7 & 1.24 & 1.13 & 0.91 & 326.09 & 358.70 & 400 & 310.71 & 0.95 \\
\hline 5 & 3.84 & 5 & 1.16 & 1.12 & 0.96 & 316.05 & 347.65 & 380 & 297.59 & 0.94 \\
\hline 6 & 4.85 & 3 & 0.26 & 0.28 & 1.07 & 239.91 & 263.90 & 290 & 259.64 & 1.08 \\
\hline \multirow[t]{2}{*}{7} & 3.84 & 4 & 0.26 & 0.29 & 1.10 & 150.18 & 165.20 & 180 & 167.23 & 1.11 \\
\hline & & & & & Total & 1951 & 2146 & 2360 & 1931 & 0.91 \\
\hline
\end{tabular}

Table 6. Target airflows and velocity pressures for Moderate airflow (second repetition)

\begin{tabular}{|c|c|c|c|c|c|c|c|c|c|c|}
\hline \multirow[b]{2}{*}{ BrNo } & \multirow[b]{2}{*}{ Dia } & \multirow[b]{2}{*}{ Order } & \multirow{2}{*}{$\begin{array}{l}\text { Moderate } \\
\mathrm{VP}_{\mathrm{cl}} \text { Target }\end{array}$} & \multirow{2}{*}{$\begin{array}{c}\text { The VPcl at } \\
\text { the } \\
\text { end of round } \\
2\end{array}$} & \multirow{2}{*}{$\begin{array}{l}\text { VP at the end of } \\
\text { 2nd } \\
\text { round/Target } \\
\text { VP }\end{array}$} & \multirow{2}{*}{\multicolumn{2}{|c|}{$\mathrm{Q}_{\text {final }}$}} & \multirow[b]{2}{*}{$Q_{\text {goal }}$} & \multirow[b]{2}{*}{ Q orig } & \multirow[b]{2}{*}{$\mathrm{Q}_{\text {final }} / \mathrm{Q}_{\text {target }}$} \\
\hline & & & & & & & & & & \\
\hline 1 & 4.85 & 1 & 0.40 & 0.37 & 0.94 & 294.32 & 323.75 & 350 & 272.85 & 0.93 \\
\hline 2 & 3.84 & 6 & 1.01 & 1.05 & 1.05 & 293.77 & 323.15 & 360 & 269.58 & 0.92 \\
\hline 3 & 4.85 & 2 & 0.50 & 0.53 & 1.06 & 331.09 & 364.20 & 400 & 352.65 & 1.07 \\
\hline 4 & 3.84 & 7 & 1.24 & 1.19 & 0.96 & 326.09 & 358.70 & 400 & 308.44 & 0.95 \\
\hline 5 & 3.84 & 5 & 1.16 & 1.09 & 0.94 & 316.05 & 347.65 & 380 & 290.47 & 0.92 \\
\hline 6 & 4.85 & 3 & 0.26 & 0.28 & 1.08 & 239.91 & 263.90 & 290 & 258.83 & 1.08 \\
\hline \multirow[t]{2}{*}{7} & 3.84 & 4 & 0.26 & 0.28 & 1.06 & 150.18 & 165.20 & 180 & 163.41 & 1.09 \\
\hline & & & & & Total & 1951 & 2146 & 2360 & 19162 & 0.92 \\
\hline
\end{tabular}


Table 7. Final Airflows on Each Branch at the end of Two Rounds of Adjustment

\begin{tabular}{|c|c|c|c|c|c|c|}
\hline Branch No & Low & Low & Moderate & Moderate & Perfect & Perfect \\
\hline 1 & 220.70 & 230.00 & 278.48 & 272.85 & 305.43 & 307.33 \\
\hline 2 & 212.63 & 209.62 & 268.01 & 269.58 & 288.38 & 291.82 \\
\hline 3 & 257.45 & 263.10 & 349.74 & 352.65 & 341.65 & 346.16 \\
\hline 4 & 232.07 & 231.63 & 310.71 & 308.44 & 342.47 & 351.38 \\
\hline 5 & 254.17 & 233.45 & 297.59 & 290.47 & 317.77 & 318.33 \\
\hline 6 & 177.36 & 169.47 & 259.64 & 258.83 & 272.51 & 271.32 \\
\hline 7 & 108.22 & 106.00 & 167.23 & 163.41 & 166.48 & 172.30 \\
\hline$\underline{\text { Fan }}$ & $\underline{1462}$ & $\underline{1443}$ & $\underline{1931}$ & $\underline{1916}$ & $\underline{2034}$ & $\underline{2058}$ \\
\hline
\end{tabular}

Table 8. Pipefactors for each branch Number

\begin{tabular}{|c|c|c|}
\hline Levels of Airflow & Branch No. & Pipefactor \\
\hline Low & 1 & 0.896 \\
\hline Low & 2 & 0.898 \\
\hline Low & 3 & 0.926 \\
\hline Low & 4 & 0.889 \\
\hline Low & 5 & 0.943 \\
\hline Low & 6 & 0.9 \\
\hline Low & 7 & 0.895 \\
\hline Low & 1 & 0.93 \\
\hline Low & 2 & 0.882 \\
\hline Low & 3 & 0.948 \\
\hline Low & 4 & 0.88 \\
\hline Low & 5 & 0.904 \\
\hline Low & 6 & 0.885 \\
\hline Low & 7 & 0.877 \\
\hline Moderate & 1 & 0.868 \\
\hline Moderate & 2 & 0.867 \\
\hline Moderate & 3 & 0.913 \\
\hline
\end{tabular}


Table 8. Pipefactors for each branch Number (Contd.)

\begin{tabular}{|c|c|c|}
\hline Levels of Airflow & Branch No. & Pipefactor \\
\hline Moderate & 4 & 0.897 \\
\hline Moderate & 5 & 0.863 \\
\hline Moderate & 6 & 0.942 \\
\hline Moderate & 7 & 0.954 \\
\hline Moderate & 1 & 0.862 \\
\hline Moderate & 2 & 0.807 \\
\hline Moderate & 3 & 0.931 \\
\hline Moderate & 4 & 0.869 \\
\hline Moderate & 5 & 0.855 \\
\hline Moderate & 6 & 0.935 \\
\hline Moderate & 7 & 0.95 \\
\hline Perfect & 1 & 0.873 \\
\hline Perfect & 2 & 0.845 \\
\hline Perfect & 3 & 0.872 \\
\hline Perfect & 4 & 0.885 \\
\hline Perfect & 5 & 0.856 \\
\hline Perfect & 6 & 0.91 \\
\hline Perfect & 7 & 0.892 \\
\hline Perfect & 1 & 0.871 \\
\hline Perfect & 2 & 0.847 \\
\hline Perfect & 3 & 0.871 \\
\hline Perfect & 4 & 0.896 \\
\hline Perfect & 5 & 0.851 \\
\hline Perfect & 6 & 0.913 \\
\hline Perfect & 7 & 0.919 \\
\hline
\end{tabular}


Appendix 4.

SAS program

\section{Data;}

Input Airflow Branch Pfactor;

Cards;

$\begin{array}{lll}1 & 1 & 0.896 \\ 1 & 2 & 0.898 \\ 1 & 3 & 0.926 \\ 1 & 4 & 0.889 \\ 1 & 5 & 0.943 \\ 1 & 6 & 0.900 \\ 1 & 7 & 0.895 \\ 1 & 1 & 0.930 \\ 1 & 2 & 0.882 \\ 1 & 3 & 0.948 \\ 1 & 4 & 0.880 \\ 1 & 5 & 0.904 \\ 1 & 6 & 0.885 \\ 1 & 7 & 0.877 \\ 2 & 1 & 0.868 \\ 2 & 2 & 0.867 \\ 2 & 3 & 0.913 \\ 2 & 4 & 0.897 \\ 2 & 5 & 0.863 \\ 2 & 6 & 0.942 \\ 2 & 7 & 0.954 \\ 2 & 1 & 0.862 \\ 2 & 2 & 0.807 \\ 2 & 3 & 0.931 \\ 2 & 4 & 0.869 \\ 2 & 5 & 0.855 \\ & 6 & 0.935\end{array}$




$\begin{array}{lll}2 & 7 & 0.950 \\ 3 & 1 & 0.873 \\ 3 & 2 & 0.845 \\ 3 & 3 & 0.872 \\ 3 & 4 & 0.885 \\ 3 & 5 & 0.856 \\ 3 & 6 & 0.910 \\ 3 & 7 & 0.892 \\ 3 & 1 & 0.871 \\ 3 & 2 & 0.847 \\ 3 & 3 & 0.871 \\ 3 & 4 & 0.896 \\ 3 & 5 & 0.851 \\ 3 & 6 & 0.913 \\ 3 & 7 & 0.919 \\ \text { run; } & & \end{array}$

\section{Proc GLM;}

Class airflow branch;

Model Pfactor $=$ Airflow Branch Airflow*Branch;

run;

ESTIMATE 'H0: $(\mathrm{B} 1+\mathrm{B} 3+\mathrm{B} 6) / 3=(\mathrm{B} 2+\mathrm{B} 4+\mathrm{B} 5+\mathrm{B} 7) / 4$ ' Branch 4 -3 4 -3 -3 4 -3 /DIVISOR=12;

Contrast 'H0: $(\mathrm{B} 1+\mathrm{B} 3+\mathrm{B} 6) / 3=(\mathrm{B} 2+\mathrm{B} 4+\mathrm{B} 5+\mathrm{B} 7) / 4$ ' Branch 4 -3 4 -3 -3 4 -3 /DIVISOR=12; 